\title{
Performance Level of the Productive Families Preparation Centers for their Developmental Roles and Its Relation to some Demographic and Social Variables Related to the Trainees in Rural Areas of Giza Governorate Ibrahim, I. F. A.; E. A. M. Heikal and Suzan M. M. Nasrat Rural Sociology and Agricultural Extension depet. Faculty of agriculture, Cairo University

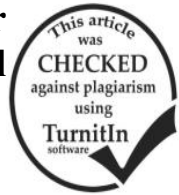

\section{مستوي أداء مراكز إعداد الأسر المنتجة الريفية لأدوارها التتموية وعلاقته ببعض المتغيرات الديموجرافية والاجتماعية

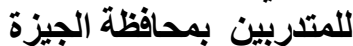

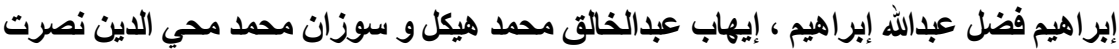

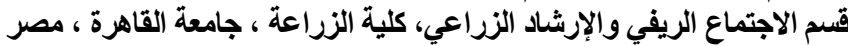

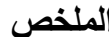

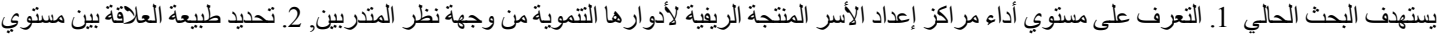

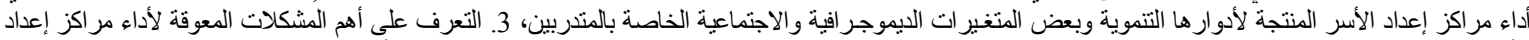

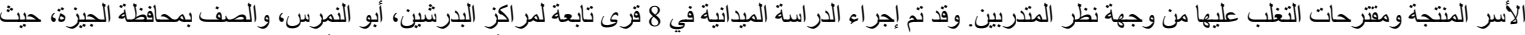

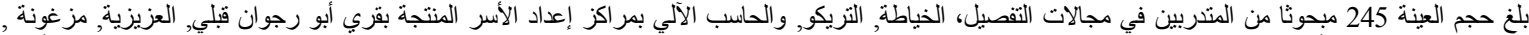

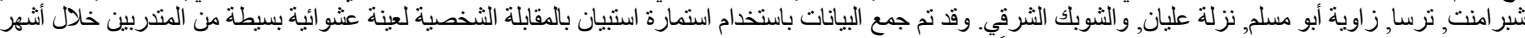

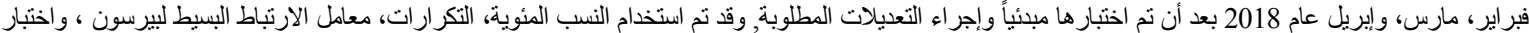

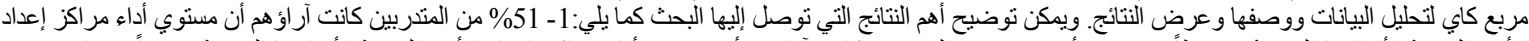

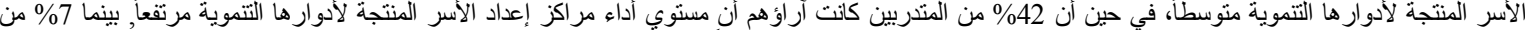

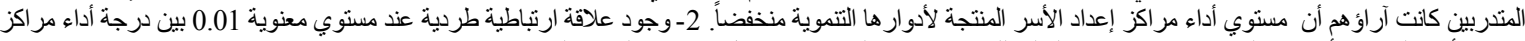

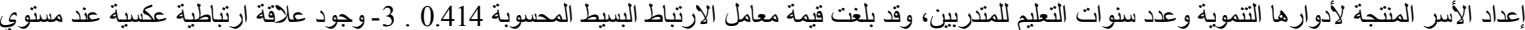

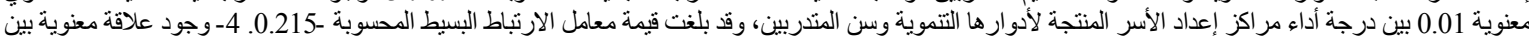

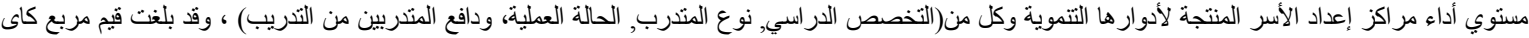

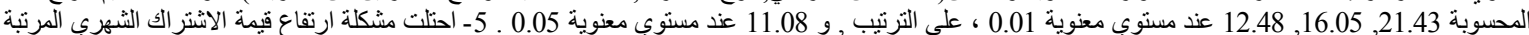

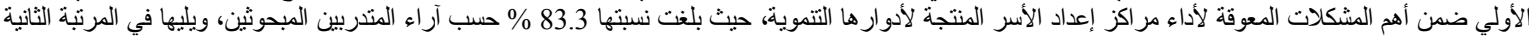

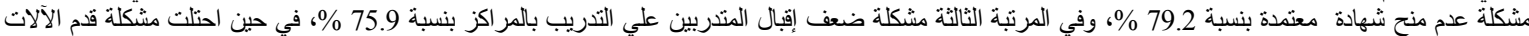

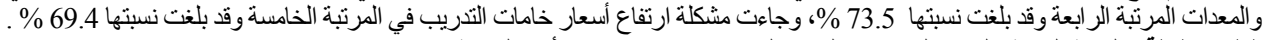

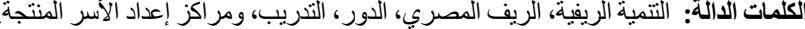

طاقات منتجة باستثمار الوقت والخامات البيئية المتاحة . (لائحة الأسر المنتجة

وتقوم مراكز إعداد الأسر المنتجة بدور هام يتمثل في" إكساب

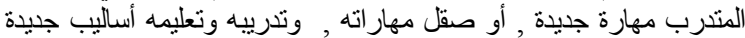
وتتمية اتجاهاته , مع إمكانية قياس مدى التطور فى المعرفة أو الممارسة , و و

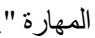

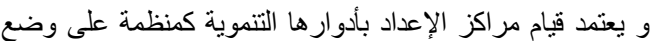

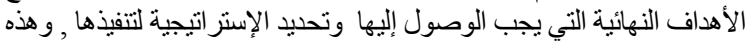
المرحلة تتطلب تحديد الأهداف ووضع السياسات التى فى ضورئها يُّنف الدور. (Joho, $1986: 42$ )

و موضو ع الأداء من الموضو عات التى تنشغل اهتمامات المجتمعات

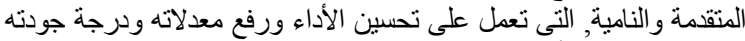

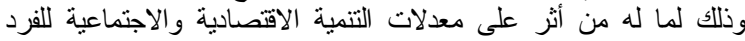

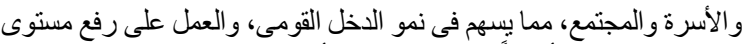

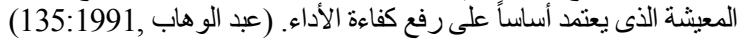
ويعد قياس مستوي أداء مراكز إعداد الأسر المناء المنتجة كمنظمة

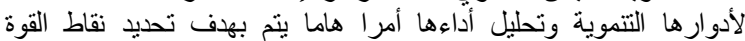

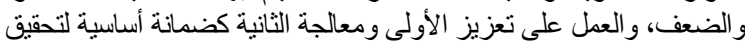

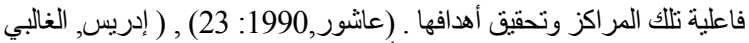

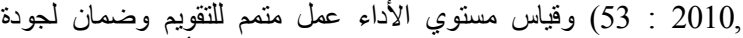

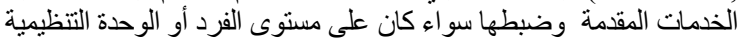

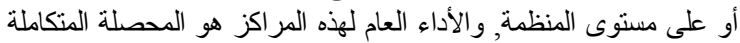
لنتائج أعمالها وتفاعلها مع بيئتها الداخلية أو الخارجية. (مشروع تأسيس الخيس

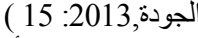

وقياس الأداء سواء علي مسنوي العاملين أو المنظمة يقصد به تحليل

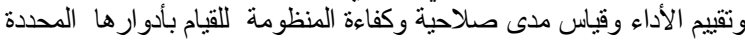
لها وفقا للإستراتيجية الموضوعة لتحقيق أهداف المنظمة ( 39 : 2001

وينطلق الإطار النظري في هذه الدراسة من مدخل الأهداف ووفقا

(Bhaskar,

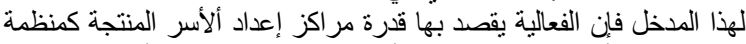

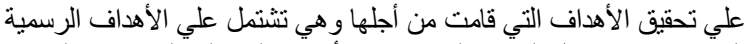

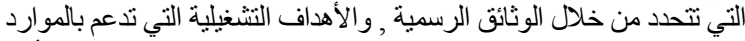
ويتم الععل فعلا علي تنفيذها (Charles 1979: 209) ولقياس الرنية مستوي الأداء
المقدمة

لا شك أن الريف كان وسيظل هو العمود الفقري للمجتمع المصري المبري

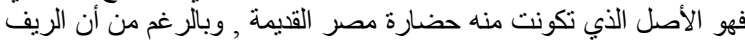

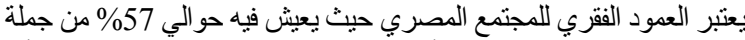

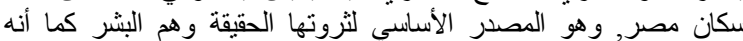

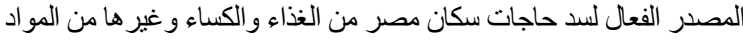

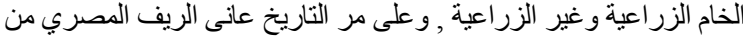

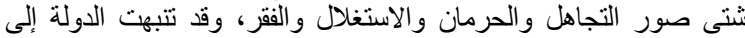

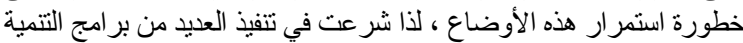

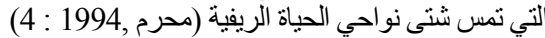

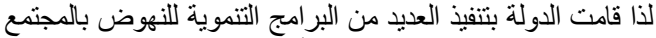

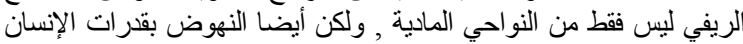

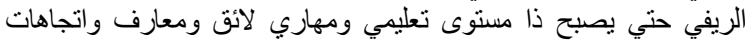

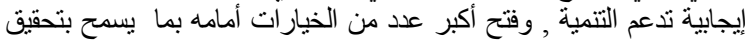

مستوي حياة أفضل . (خضر ر و وآخرون , 2010 : 94 ) ) و يعد برنامج الأسر المنتجة أحد أهم البرامج التماعت التموية المتميزة في

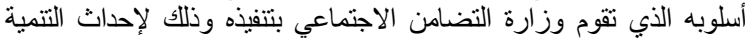

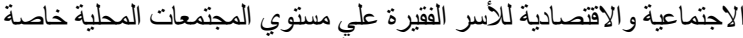

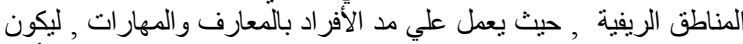

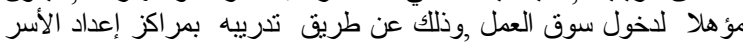

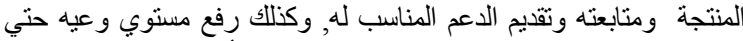

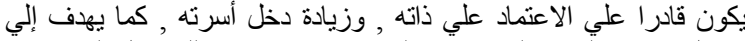

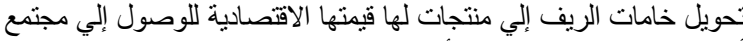

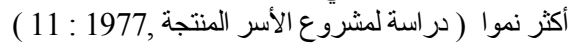
ويقوم برنامج الأسر المنتجة علي ثلاث محاور رئيسية الأنية

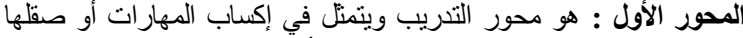

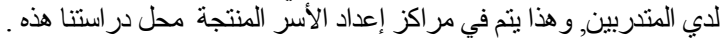

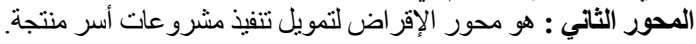

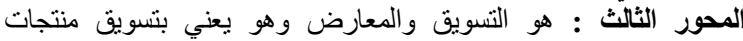
المشرو عات التي فام بإنتاجها المستفيدين بتنفيذها.

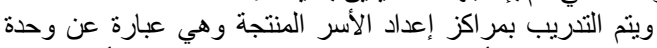

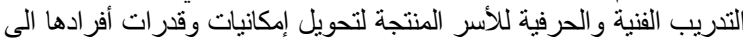


نسمة وفقا لتعداد 2016 , تتضمن محافظة الجيزة 10مر اكز ادارية, 154 قرية

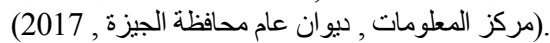

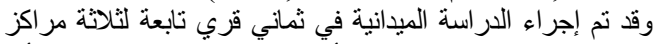

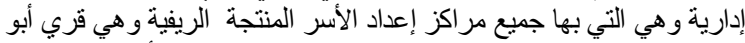

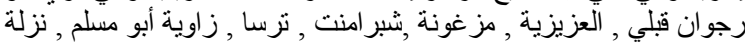
عليان , الثوبك الثرقي

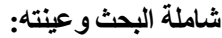

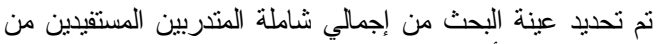

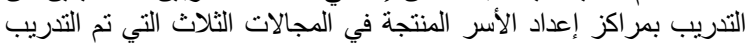

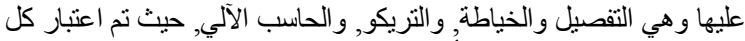

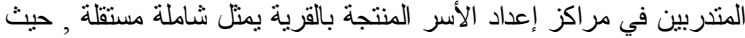

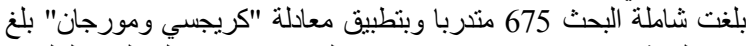

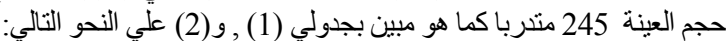

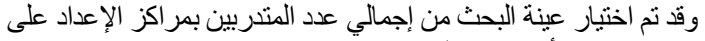

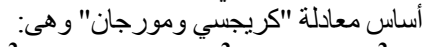
$S=X^{2}$ PN ( 1-P ) $\div d^{2}$ ( N-1 ) + X P (1-P) حيث أن :

= S

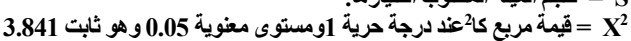

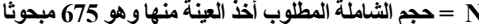

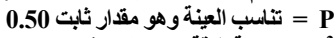

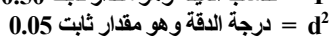

وبتطبيق المعادلة السابقة بلغ حجم عبنة البحث 245 مبحوثا.

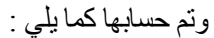

بم لبنة لنطليب =

جدول 1 ـ توزيع شاملة البحث والعينة بمراكز إعداد الأسر المنتجة وفقا للمجالات المدروسة

\begin{tabular}{|c|c|c|c|c|c|}
\hline \multicolumn{3}{|c|}{ المتكربين } & \multirow{2}{*}{ القرية } & \multirow[b]{2}{*}{ r } & \multirow{2}{*}{ المركز الإداري } \\
\hline$\%$ & العينة & الثشاملة & & & \\
\hline 36.6 & 37 & 101 & أبو رجوان قبلي & 1 & \\
\hline 36.5 & 27 & 74 & العزيزية & 2 & البدرشين \\
\hline 36.2 & 42 & 116 & مز غونة & 3 & \\
\hline 36.4 & 106 & 291 & إجمالي البدرشين & & \\
\hline 36.4 & 39 & 107 & شبرامنت & 4 & \\
\hline 36.3 & 33 & 91 & ترسا & 5 & أبو النمرس \\
\hline 36.4 & 32 & 88 & زاوية أبو مسلم & 6 & \\
\hline 36.4 & 104 & 286 & جمالي أبو النمرس & & \\
\hline 35.5 & 11 & 31 & نزلة عليان & 7 & الإن \\
\hline 35.8 & 24 & 67 & الثوبك الثرقي & 8 & الصف \\
\hline 35.7 & 35 & 98 & إجمالى الصف & & \\
\hline 36.3 & 245 & 675 & إجمالي عام & & \\
\hline
\end{tabular}

جدول 2 ـ توزيع عينة البحث بمراكز إعداد الأسر المنتجة وفقا للمجالات المدروسة ع نائة

\begin{tabular}{|c|c|c|c|c|c|c|}
\hline \multicolumn{4}{|c|}{ عدد عينة متـربي كل حرفة } & \multirow{2}{*}{ القرية } & \multirow[b]{2}{*}{ p } & \multirow[b]{2}{*}{ لمركز الإداري } \\
\hline إجمالي & حاسب & تريكو & تفصيل & & & \\
\hline 37 & 18 & 9 & 11 & أبو رجوان قبلي & 1 & \\
\hline 27 & 18 & 0 & 9 & العزيزية & 2 & البدرشين \\
\hline 42 & 21 & 8 & 13 & 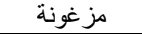 & 3 & \\
\hline 106 & 57 & 17 & 32 & إجمالي & & \\
\hline 39 & 24 & 0 & 15 & شبر امنت & 4 & \\
\hline 33 & 16 & 8 & 9 & ترسا & 5 & أبو النمرس - ل ألمر \\
\hline 32 & 15 & 7 & 10 & زاوية أبو مسلم & 6 & \\
\hline 104 & 54 & 15 & 35 & إجمالي & & \\
\hline 11 & 0 & 5 & 6 & 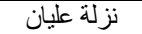 & 7 & \\
\hline 24 & 16 & 0 & 8 & الثوبك الثرقي & 8 & الصف \\
\hline 35 & 16 & 5 & 14 & إجمالي & & \\
\hline 245 & 127 & 38 & 80 & إجمالي عام & & \\
\hline
\end{tabular}

بمر اكز الإعداد يوضع في الاعتبار العوامل المباشرة وغير المباثرة التي ولثي

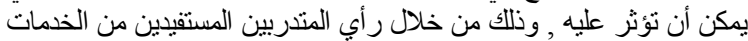

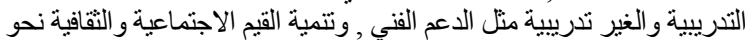

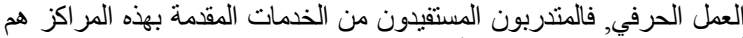
أقدر علي الحكم علي مستوي أداءها.

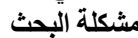

تقوم مر اكز إعداد الأسر المنتجة منذ نشأتها في نهاية الستينات من

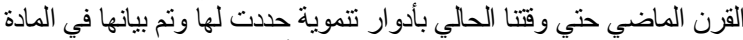

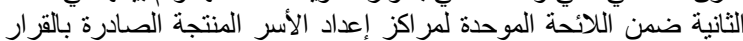

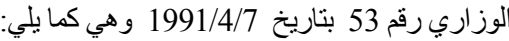

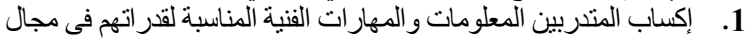

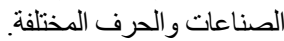

2. تقديم الدعم الفني للمتدربين في مجال الصنية الصناعات والحئة الحرف المختلفة.

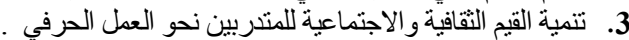

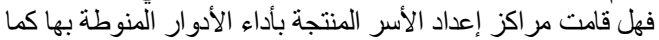

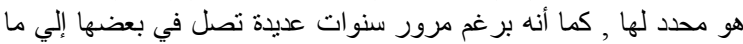
يقرب من خمسين سنة علي إنشاء تلك المر اكز إلا أنها لم تحظ باهي باهتمام البحث

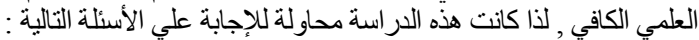

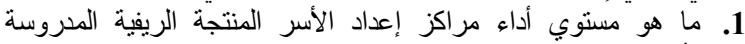

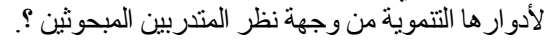

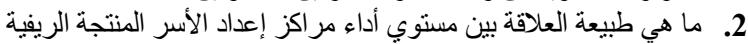

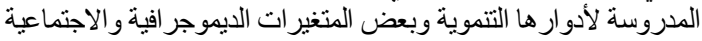

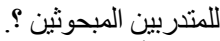
3. ما هي أهم المشكلات المعوقة لأداء مر اكز إعداد الأسر المنتجة , وأهم

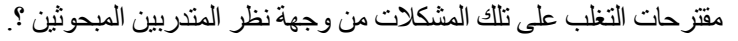
الهداف البحث 1. التعرف على مستوي أداء مر اكز إعداد الأسر المنتجة الريفية المدروسة

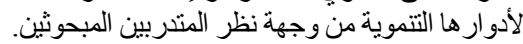

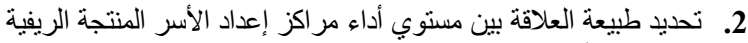

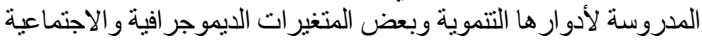

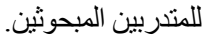

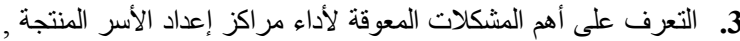
وأهم مقترحات التغلب على تلك المشكلات من وجهة نظر المناء المندربين

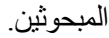

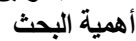

تتمنل أهمية هذا البحث في أن النتائج التي يسعي للوصول إليهاو إوباء

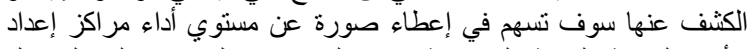

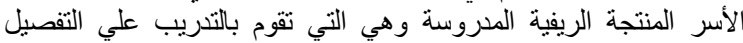

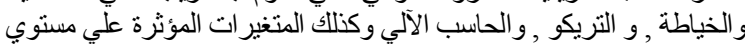

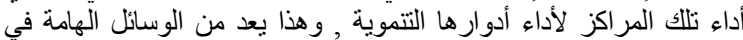

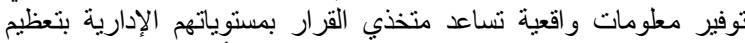

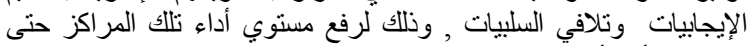

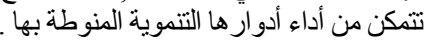

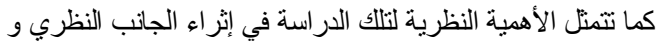

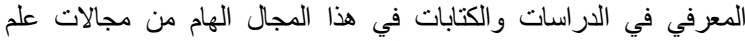

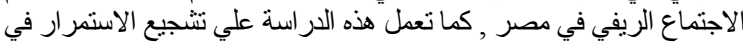

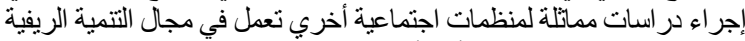

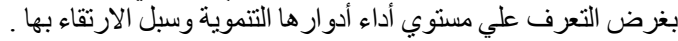

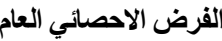

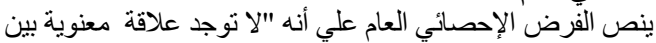

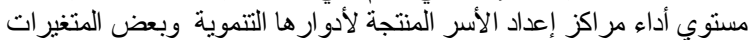

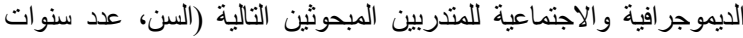

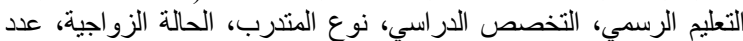

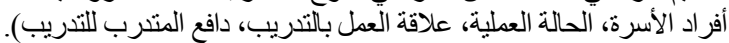

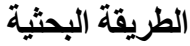

تم اختيار محافظة الجيزة كمجال جغر افي لإجر اء البحث علي اعتبار

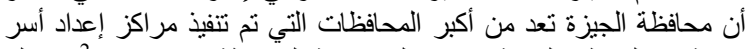

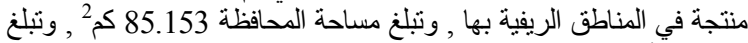

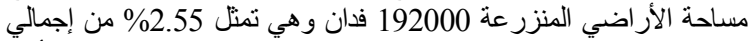
المساحة المنزر عة علي مسنوي الجمهورية , ويلتغ عدد السكان 8.759 ألف فئ 
4. الاعم الفنى: ويقصد به تحديد مستوي أداء مراكز إعداد الأسر المنتجة

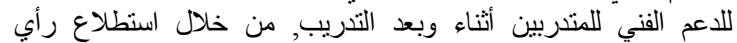

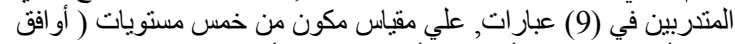

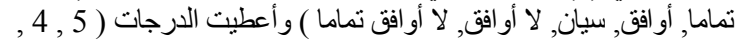

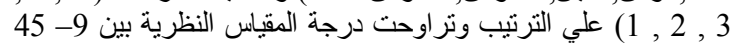

درجة.

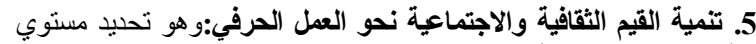

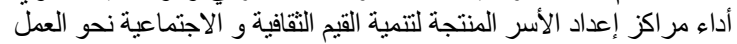

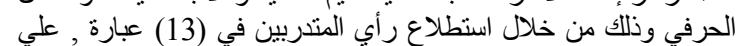

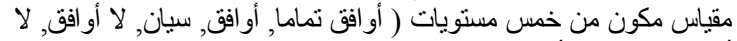

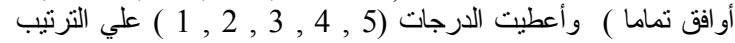

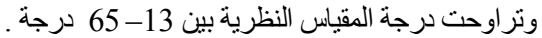

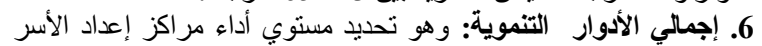

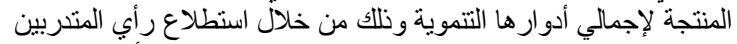

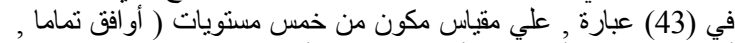

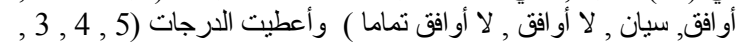

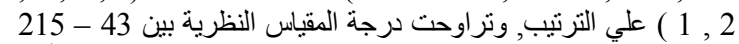

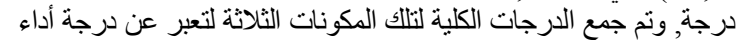

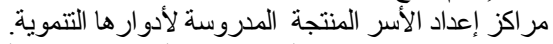

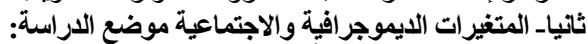

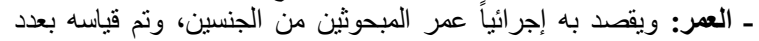
السنوات الخام وقت استبيانه.

- الحالة الزواجية: ويقصد بها الحالة الزواجية الزية للمبحوثين وقت تطبيق

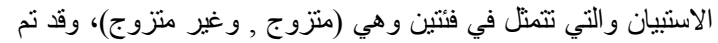

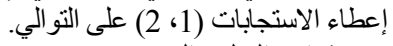

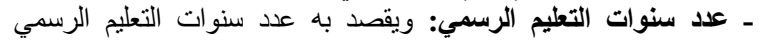
للمبحوثين من الجنسين، ولَّياسه نم استخدام الرقم الخام لعدد سنوات التريم

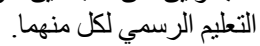

ـ عدد أفراد الأسرة: ويقصد به لعدة عدد الأفراد الذين يعيشون معاً، ويشتركون في

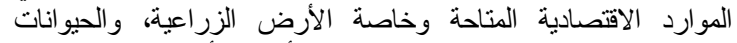
المزرعية ، ولقياسه استخدم الرقم الخام لعدد الأفر اد بالأسرة.

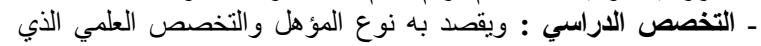

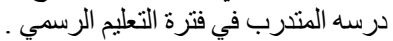

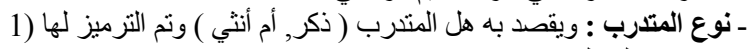

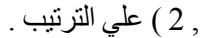

الحالة العملية : ويقصد به هل الترتيب المتدرب (يعمل أم لا يعمل) وقت تطبيق

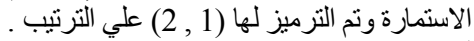

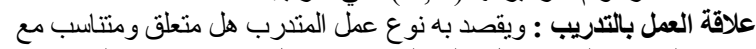

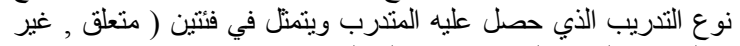

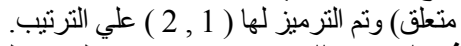

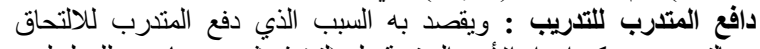

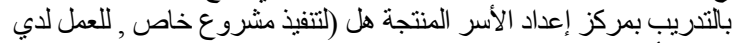

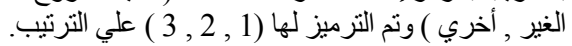

جمع البيانات وأدوات التحليل الإحصائي:

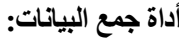

تم استخدام استمارة الاستبيان بالمقابلة الثخصية للحصول علي التباني

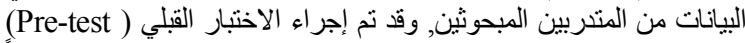
بتطبيق استمارة الاستييان علي عينة عشو ائية بسيطة مكونة من الين 15 متدرباً

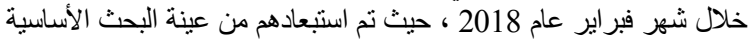

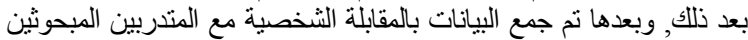
في الفترة من فبر اير حتى إبريل 2018 الإندي

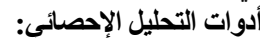

تم استخدام التكرارات والني: النسب المئوية من خلال الجداول التكرارية

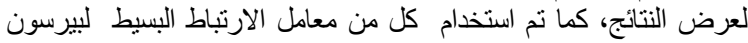
"Pearson Product Correlation Coefficient" كاي "Chi square"، وذلك لاختبار معنوية العلاقات بين درجة أداء مر اكز مرئ

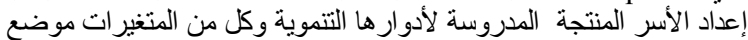

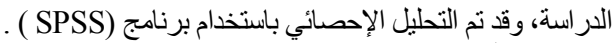

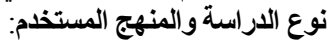

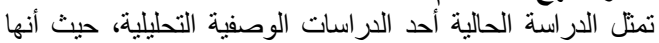

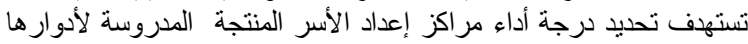

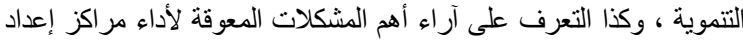

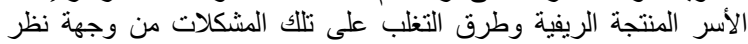

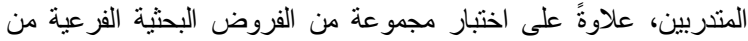

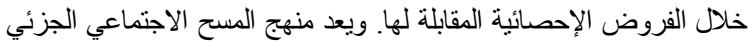

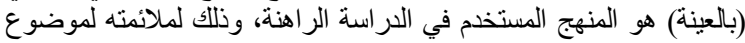

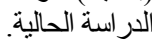

المفاهيم الإجرائية للمتغيرات وطرق قياسها:

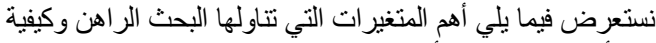

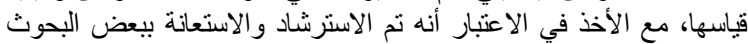

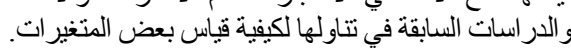

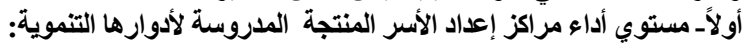

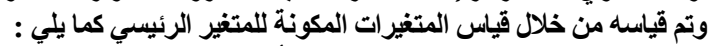

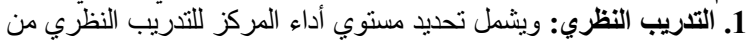

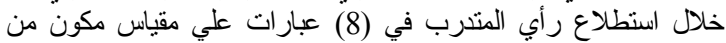

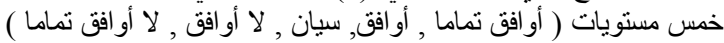

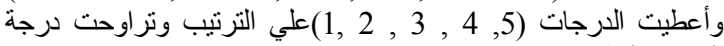
المقياس النظرية بين 8 - 40 درجة 2.التدريب العملي: ويشمل تحديد مستوي أداء مر اكز إعداد الأسر المنتجة

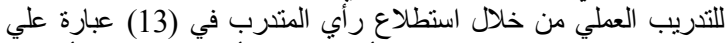

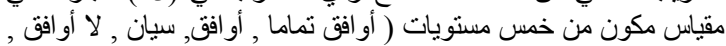

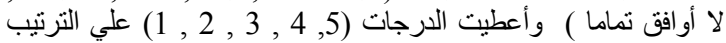

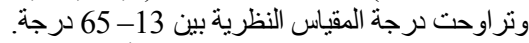

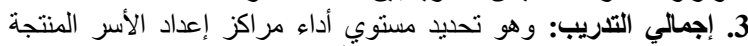

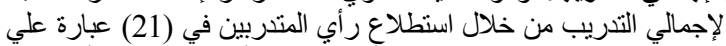

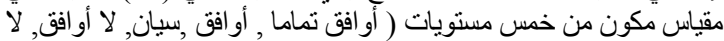

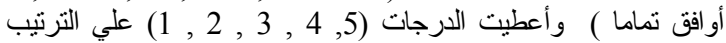
وتر اوحت درجة المقياس النظرية بين 21 - 110 درجة 11 درجة .

\begin{tabular}{|c|c|c|c|c|c|c|c|c|}
\hline$\%$ & عدد & الحالة العملية & $\%$ & عدد & نوع المبحوث & $\%$ & عدد & فُئات السن \\
\hline 43.7 & 107 & يعمل & 46.5 & 114 & ذكر & 56.3 & 138 & سن ( 15 - سنة) \\
\hline 56.3 & 138 & لآ بعمل & 53.5 & 131 & أنثي & 39.2 & 96 & السن ( 24 - سنة) \\
\hline 100 & 245 & إجمالي & 100 & 245 & إجمالَّ & 4.5 & 11 & (34-32 سنة) \\
\hline$\%$ & عدد & علاقة العمل بالتدريب & $\%$ & عدد & الحالة الزو اجية & 100 & 245 & \\
\hline 58.4 & 143 & مرتبط بالعمل & 42.9 & 105 & متزوج & $\%$ & عدد & لئيمي \\
\hline 41.6 & 102 & غير مرتبط بالعمل & 57.1 & 140 & غير متزوج & 29.4 & 72 & ن "أقلّ من 9 سنوات \\
\hline 100 & 245 & إجمالي & 100 & 245 & إجمالي & 56.7 & 139 & سط (9 - 12 سنة) \\
\hline$\%$ & عدد & الدافع للندريب & $\%$ & عدد & عدد أفر اد الآسرة & 13.9 & 34 & تفع أكثر من 12 سنة \\
\hline 17.1 & 42 & تتفيذ مشرووع خاص & 4.1 & 10 & قليل ( 1 -2 فرد) & 100 & 245 & \\
\hline 40.8 & 100 & العمل لدي الغير & 61.6 & 151 & متوسط (3- 4فرد) & $\%$ & عدد & الإر اسي \\
\hline 22.5 & 55 & للار اسّة & 34.3 & 84 & كبير ( 5-6 فرد) & 16.7 & 41 & \\
\hline 19.6 & 48 & شخصي & 100 & 245 & إجمالي & 17.1 & 42 & \\
\hline \multirow[t]{5}{*}{100} & 245 & إجمالي & & & & 18.5 & 45 & \\
\hline & & & & & & 5.7 & 14 & \\
\hline & & & & & & 5.2 & 13 & \\
\hline & & & & & & 36.8 & 90 & \\
\hline & & & & & & 100 & 245 & 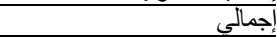 \\
\hline
\end{tabular}




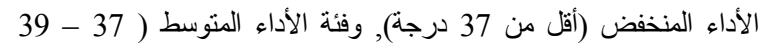

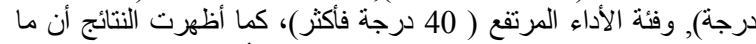

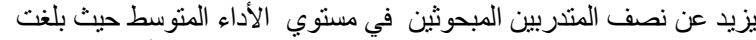

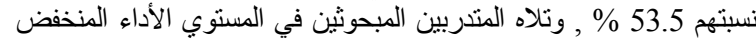

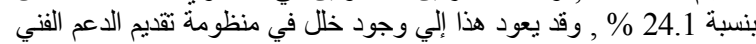

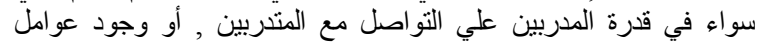
خارجية منل العادات والتقاليد التي قد تعوق عملية تقديم الدعم الفني خاصة

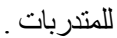

5- تنمية القيم الثقافية والاجتماعية نحو العمل الحرفي:

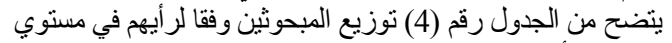

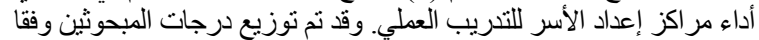

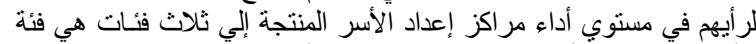

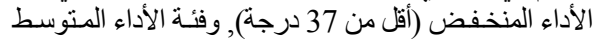

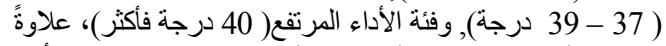

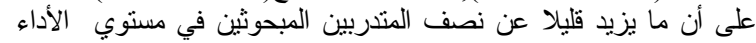

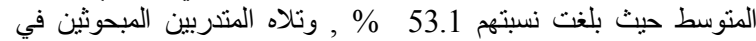

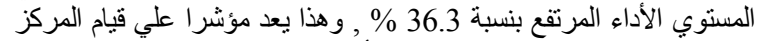

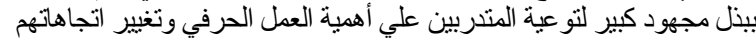

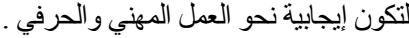

6- 6- إجمالي الأدوار التنموية:

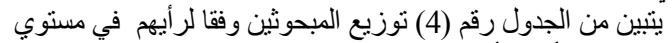

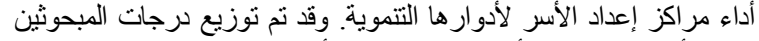

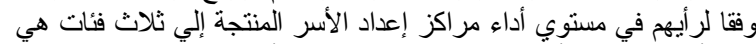

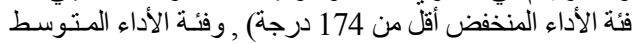

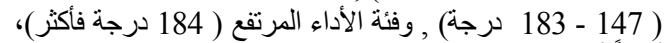

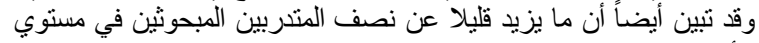

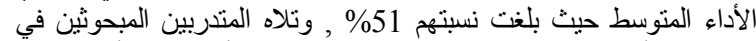

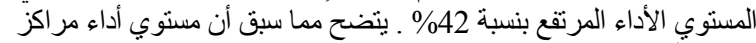

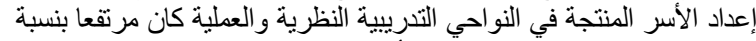

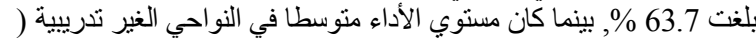

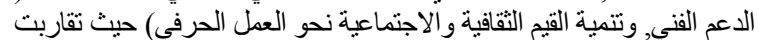

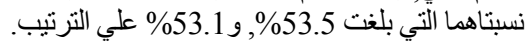

جدول 4 ـ توزيع المتدربين المبحوثين وفقآ لآرائهم في مستوى أداء مراكز

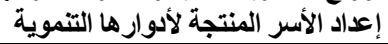

\begin{tabular}{|c|c|c|c|c|c|c|c|c|}
\hline \multirow{2}{*}{\multicolumn{2}{|c|}{ الإجمالي }} & \multicolumn{6}{|c|}{ مستوى الأداء } & \multirow{3}{*}{ لأدوار التتموية } \\
\hline & & \multicolumn{2}{|c|}{ مرتفع } & \multicolumn{2}{|c|}{ متوسط } & \multicolumn{2}{|c|}{ منخفض } & \\
\hline$\%$ & عدد & $\%$ & عدد & $\%$ & عدد ( عد & $\%$ & عدد & \\
\hline 00.0 & 245 & 54.7 & 134 & 36.3 & 89 & 9.0 & 22 & ب ب النظر \\
\hline 00.0 & 245 & 42.0 & 103 & 45.3 & 111 & 12.7 & 31 & العمل. \\
\hline 100.0 & 245 & 63.7 & 156 & 26.1 & 64 & 10.2 & 25 & ي التدريب \\
\hline 100.0 & 245 & 22.4 & 55 & 53.5 & 131 & 24.1 & 59 & لفنى (لفى \\
\hline 100.0 & 245 & 36.3 & 89 & 53.1 & 130 & 10.6 & 26 & لقتيم الثنقافية \\
\hline 100.0 & 245 & 42.0 & 103 & 51.0 & 125 & 6.9 & 17 & جمالي الأدوار \\
\hline
\end{tabular}

ثاتيا :طبيعة العلاقة بين درجة أداء مراكز إعداد الأسر المنتجة لأدوارها

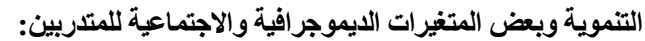

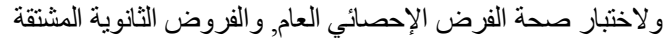

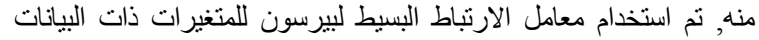

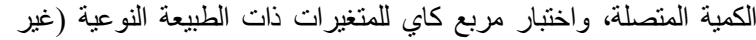
المنصلة), وتتضح النتائج كما هي مبينة بالجدولين رقم (5)، لإنير (6) علي النحو

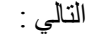

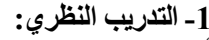

أـ نتائج التحليل الإحصائي باستخدام معامل الارتباط البسيط:

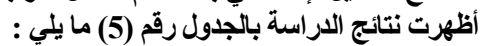

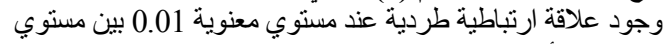

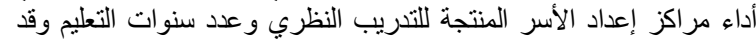

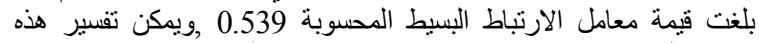

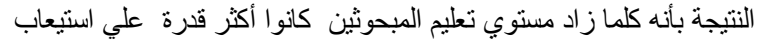

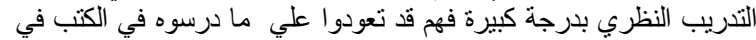

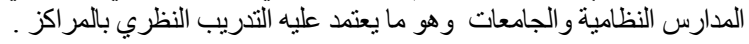

تشير البيانات الواردة بالجدول رقم (3) أن أكثر من نصف العينة في

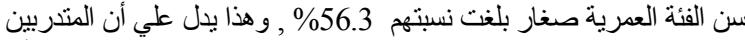

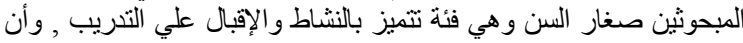

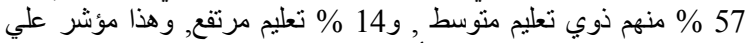

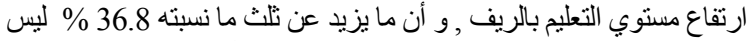

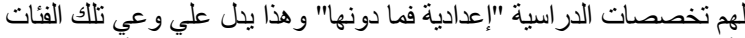

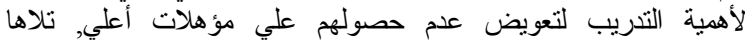

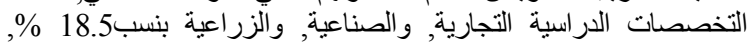

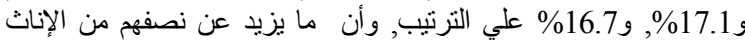

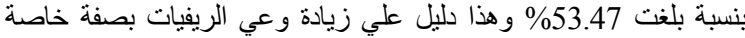

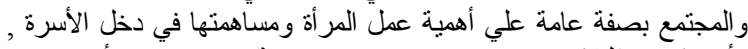

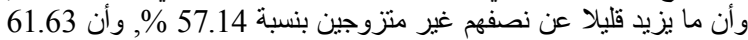

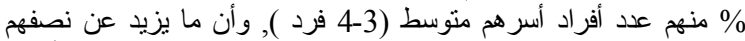

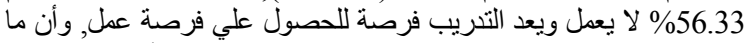

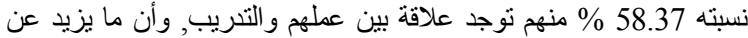

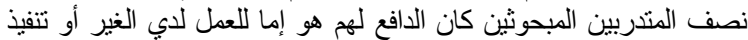

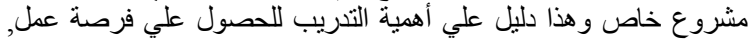

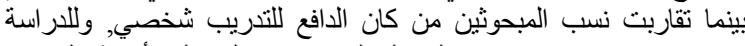

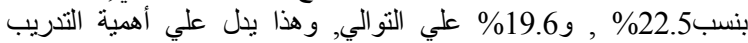
اللمجتمع ومدي التتوع في دوافع المتدربين للتدريب . التتائج والمناقشات

أولا : مستوي أداع مراكز إعداد الأسر المنتجة لأدوارها التتموية:

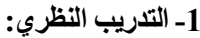

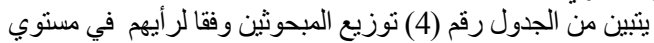

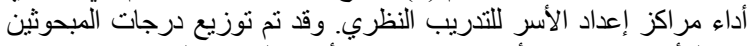

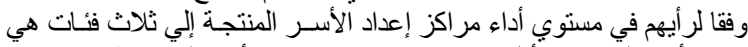

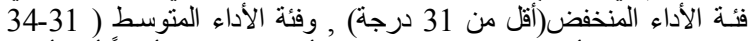

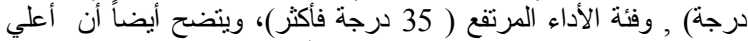

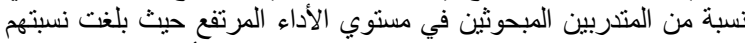

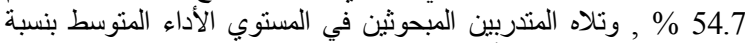

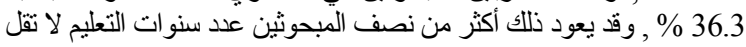

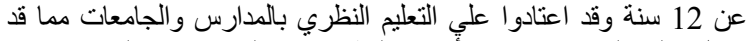
يسهل علي المدرب شرح الأجزاء النظرية من الحرفة وسهولة فهمها من

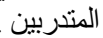

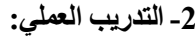

يتبين من الجدول رقم (4) توزيع المبحوثين وفقا لر أيهم في مستوي

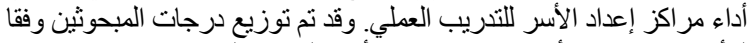

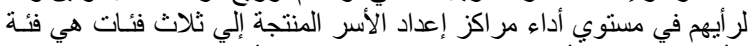

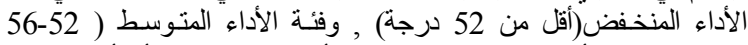

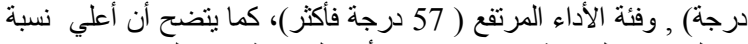

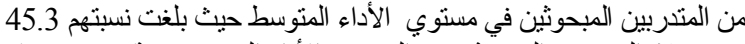

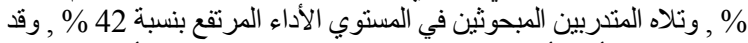

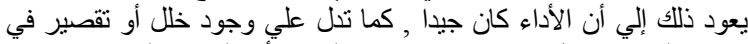

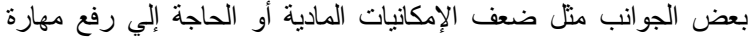
3- الجهاز الإداري والتدريبي للمر اكز الإن.

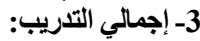

يتضح من الجدول رقم (4) توزيع المبحوثين وفقا لرأيهر في

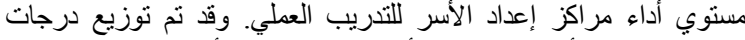

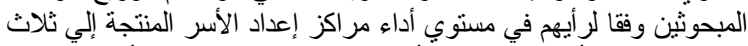

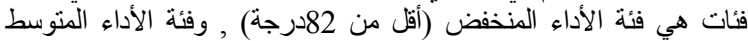

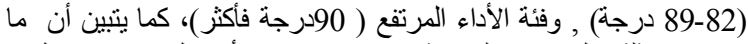

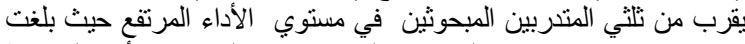

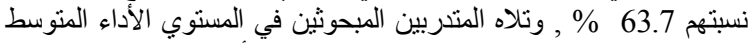

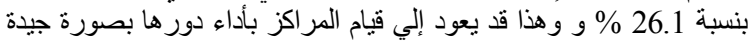
ونوفر الظروف المناسبة للقيام بالعملية التدرييية بكفاءة عالية.

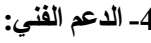

يتنين من الجدول رقم (4) توزيع المبحوثين وفقا لر أيهم في مستوي

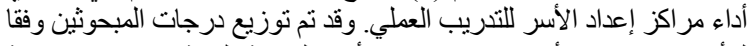

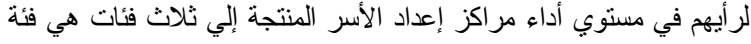


بـ نتائج التحليل الإحصائي باستخدام مربع كاي:

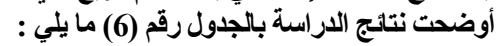

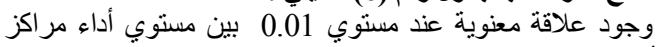

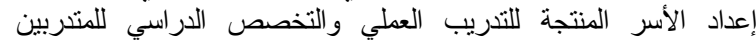

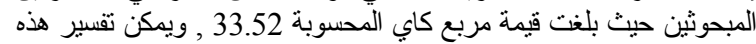

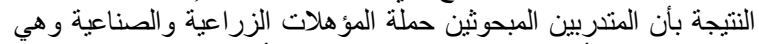

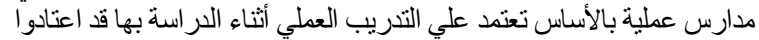

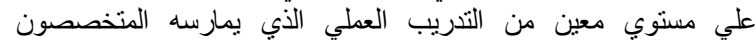

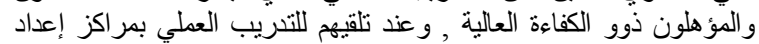

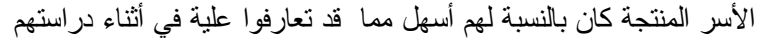

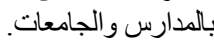
وجود علاقة معنوية عند مستوي 0.01 بين مستوي أداء مر اكز

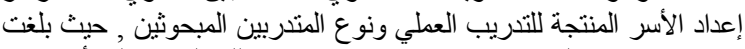

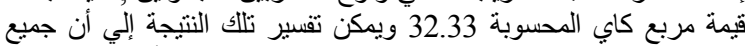

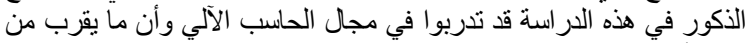

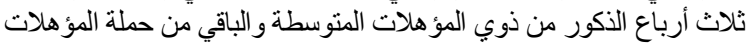

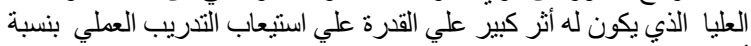

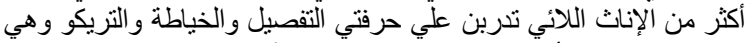

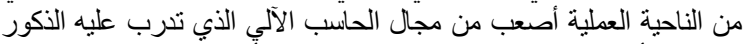

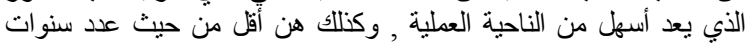

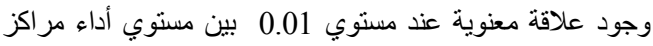

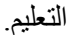

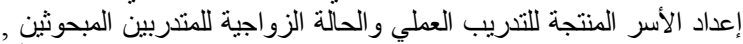

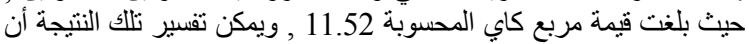

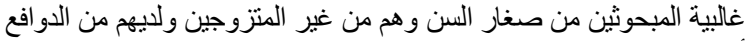

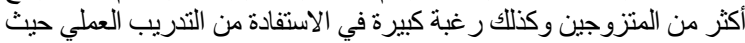

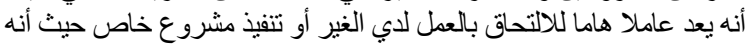

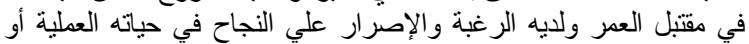

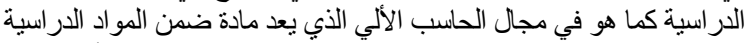

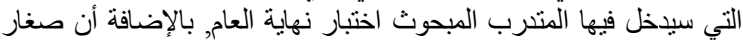

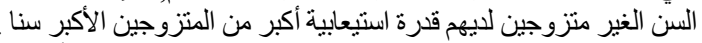

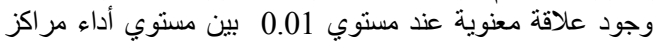

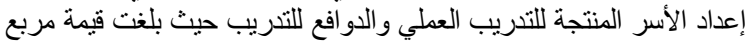

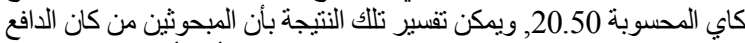

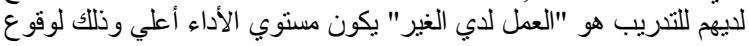

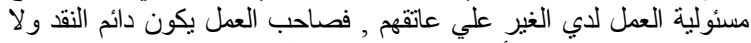

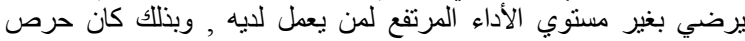

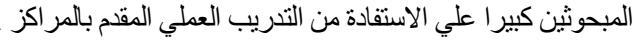

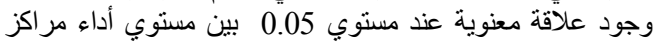

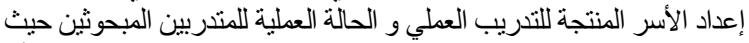

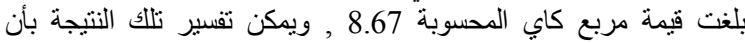

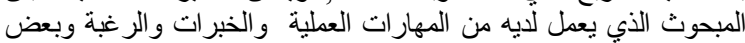

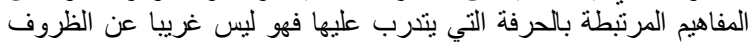

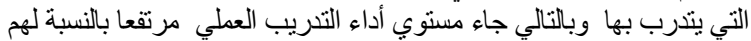

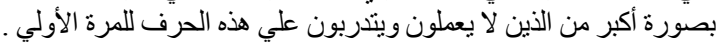

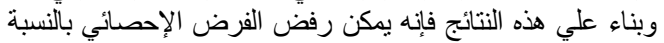

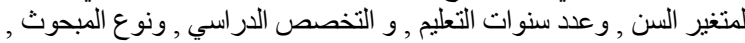

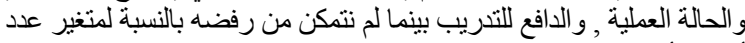
أفراد الأسرة وومتغير علاقة العة العمل بالتدريب.

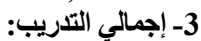
أ ـ نتائج التحليل اللتريب: الإحصائي باستخدام معامل الارتباط البسيط:

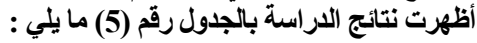

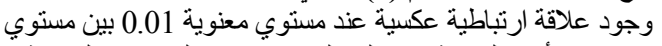

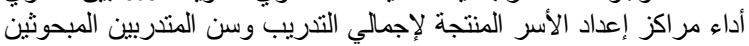

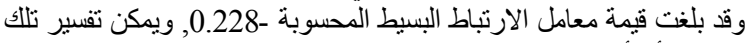

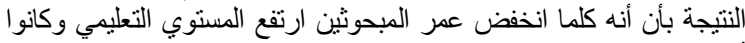

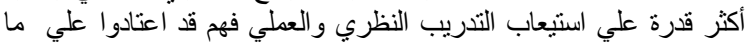

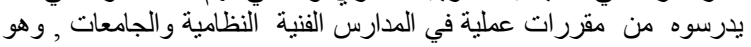

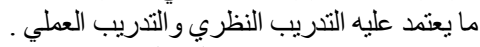

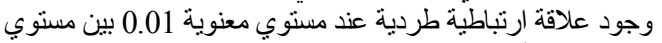

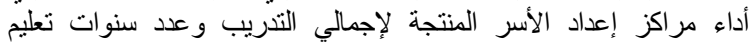
المتدربين المبحوثين وقد بلغت قيمة معامل الارنباط البسيط 0.633 , ويمكن
وجود علاقة ارتباطية عكسية عند مستوي معنوية 0.05 بين مستوي

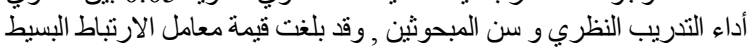

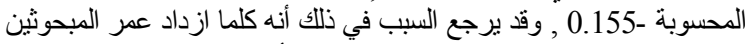

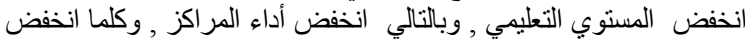

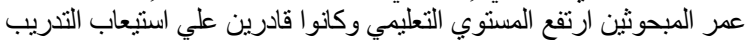

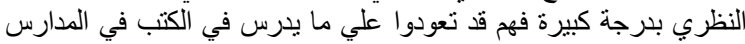

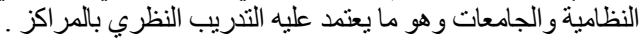

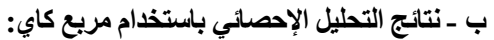

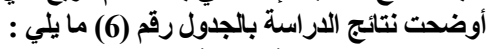

وجود علاقة معنوية عند مستوي

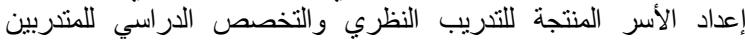

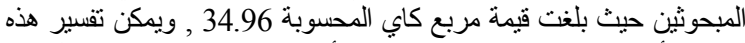

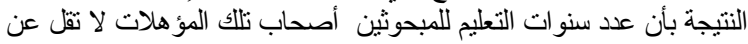

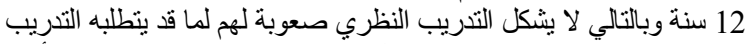

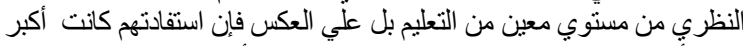

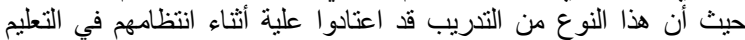

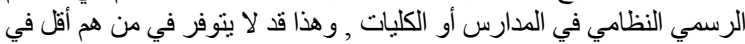

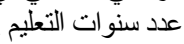

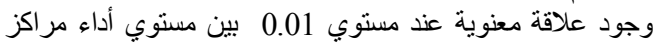

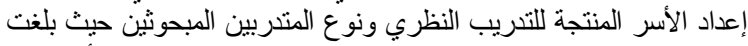

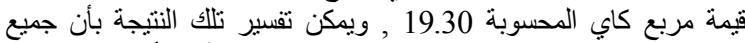

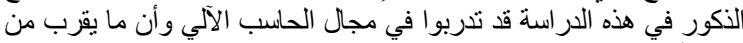

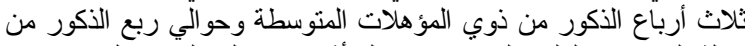

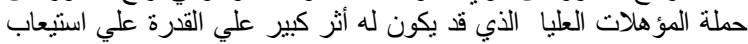

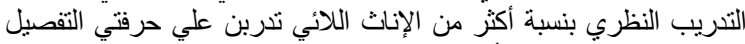

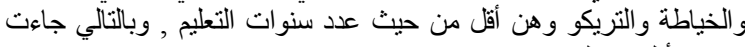

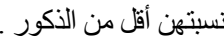

وجود علاقة معنوية عند مستوي 0.01 بين مستوي أداء مر اكز

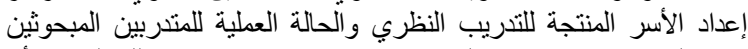

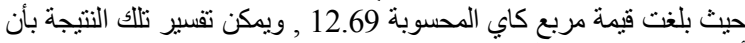

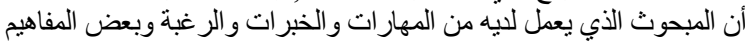

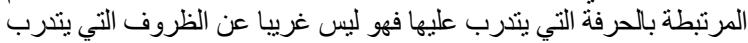

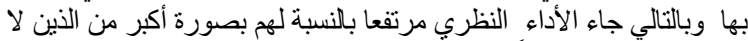

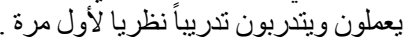

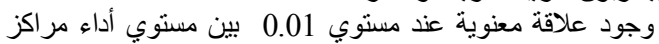

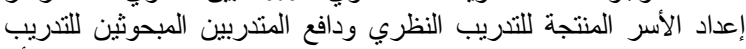

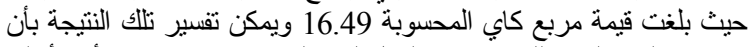
من كان الدافع لليهم للتندريب هو العي العمل لدي الغير يكون مستوي الأداء أعلي

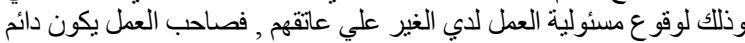

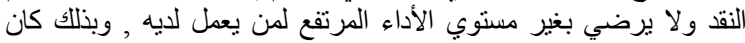

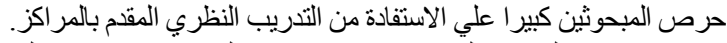

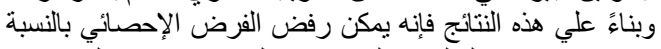

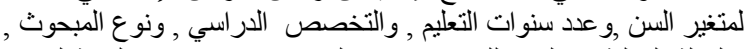

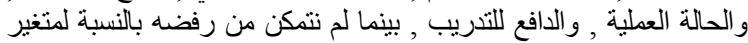
عدد أفر اد الأسرة , والحالة الزوراجية , و وعلاقة العمل بالتدريب .

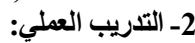
أـ نتائج التحليل الإحصائي باستخدام معامل الارتباط البسيط:

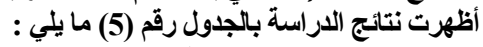

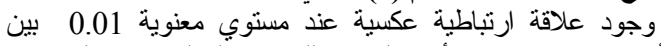

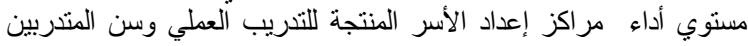

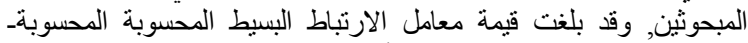

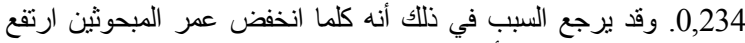

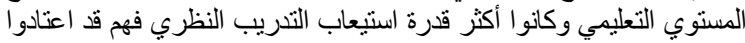
علي التندريب العملي في المدارس النظامية والجامعات وهو التئ ما يعتمد عليه

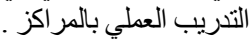

وجود علاقة ارتباطية طردية عند مستوي معنوية 0.01 مبين

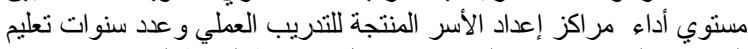

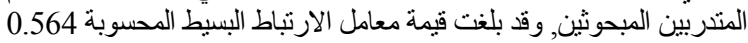

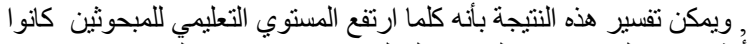

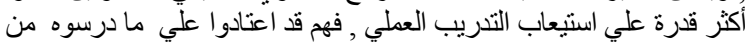

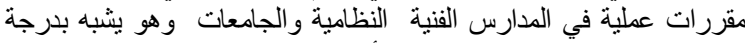
كبيرة التدريب العملي بمر اكز إعداد الأسر المنتجة . لنطية 
النتيجة أنه كلما انخفض سن المبحوثين قلت خبر اتهم في العمل ومنهم من هو

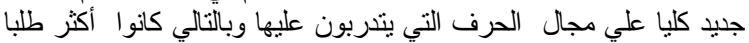

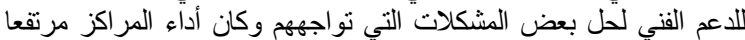

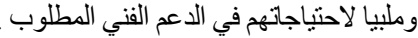
وجود علاقة ارتباطية عكسية عند مستوي معنوية 0.05 بين مستوي لإعن الإني

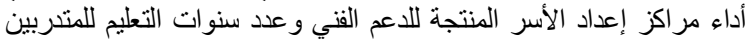

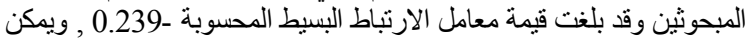
تقسير تللك النتيجة كلما ارتفع المستوي التعليمي للمبحوثين كانوا أكثر نشاطيا

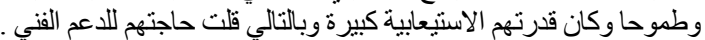

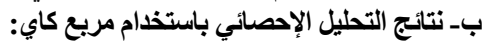

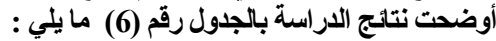

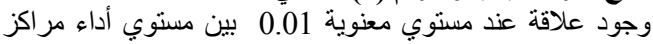

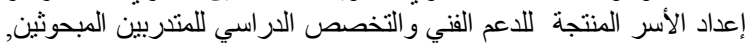

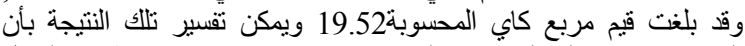

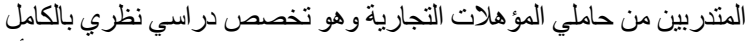

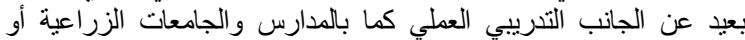

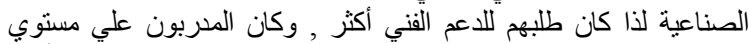

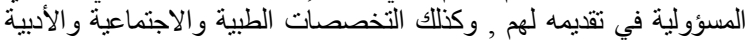

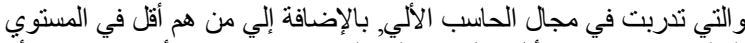

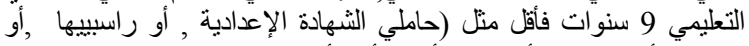

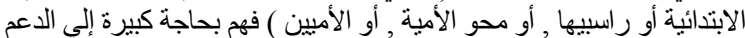

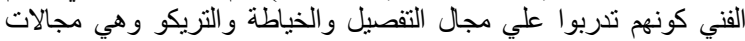

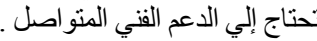

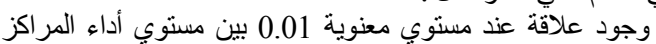

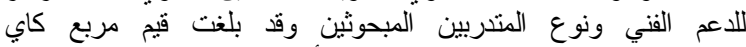

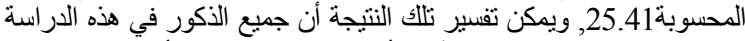

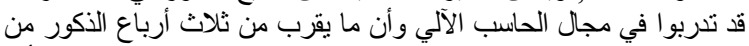

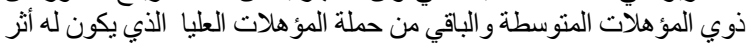

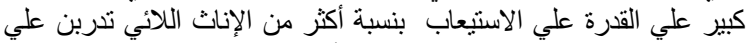

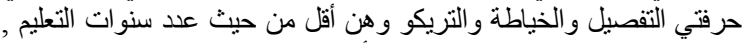

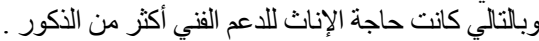

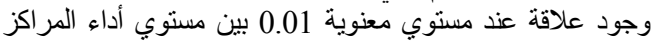

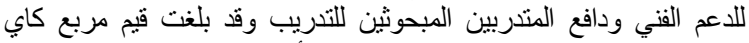

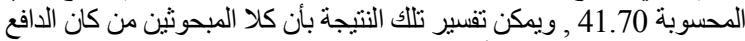

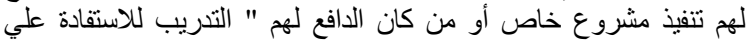

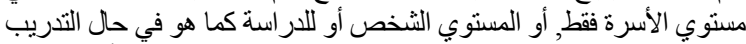

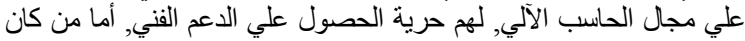

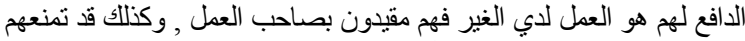

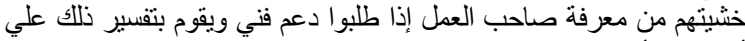

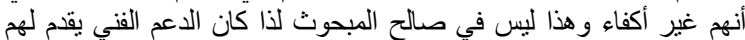

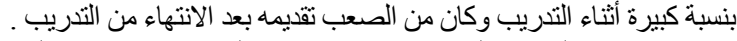

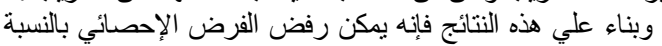

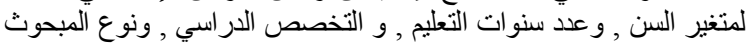

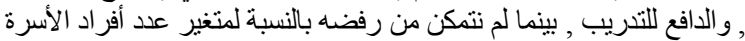

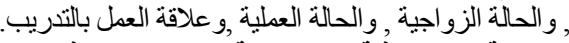

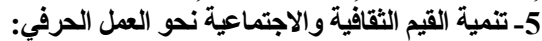

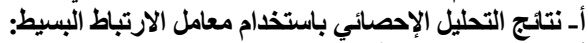

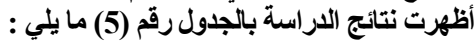

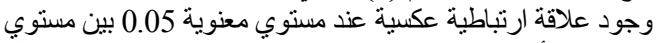
أداء مراكز إعداد الأسر المنتجة لتنمية القيم التقافية والاجتماعية نحو العية العمل

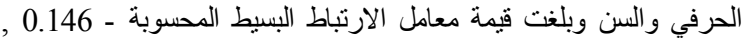

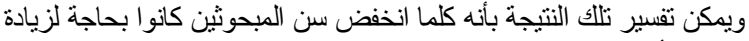

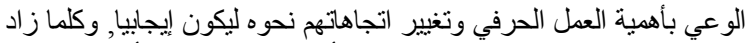

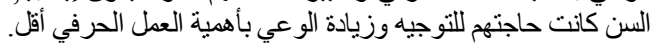

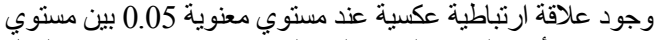

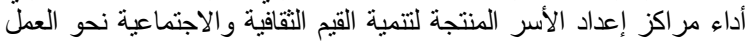

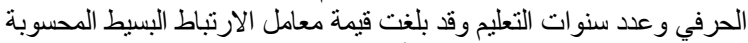

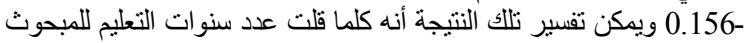

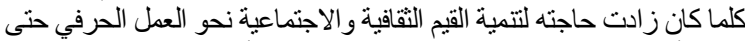

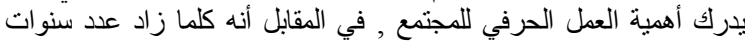

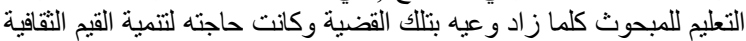

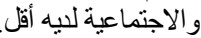

تقسير تلاك النتيجة بأن المتدربين المبحوثين كلما ارتفع المستوي التعليمي كانوا

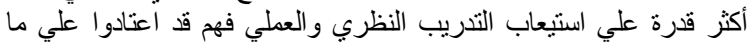

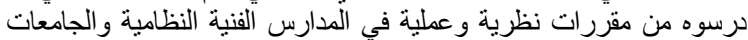
ووهو ما يعتمد عليه الثرح النظري والتدريب العملي بمراكز إعداد الأسر الفرات

المنتجة

بـ نتائج التحليل الإحصائي باستخدام مريع كاي:

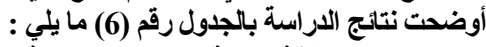

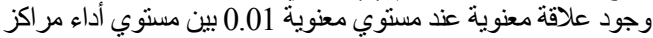

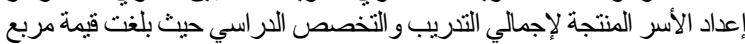

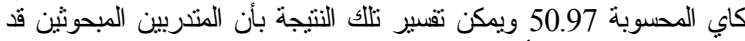

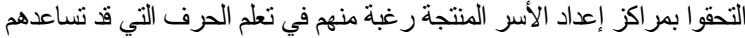

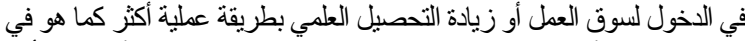

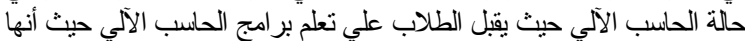

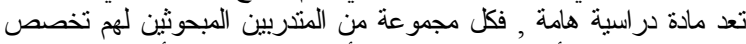

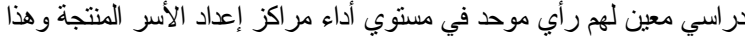

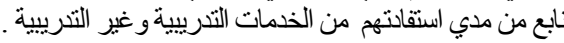

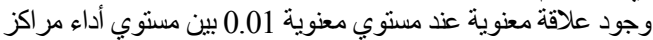

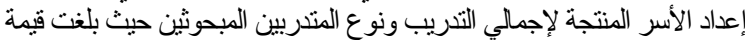

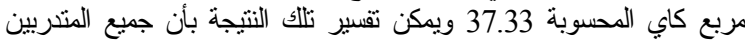

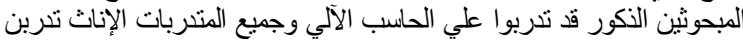

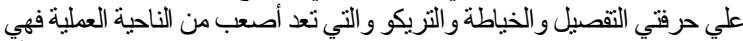

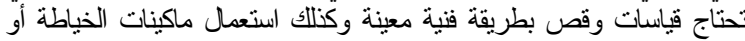

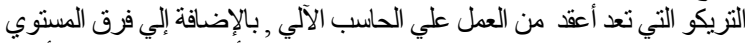

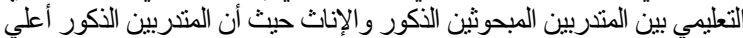
في المستوي التعليمي من الإناث.

وجود علاقة معنوية عند مستوب معنوية 0.01 بين مستوبي أداء مر اكز الإنز

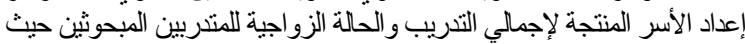

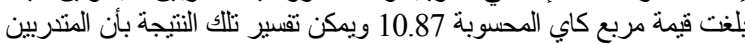

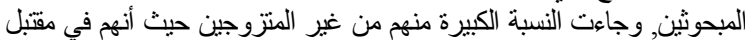

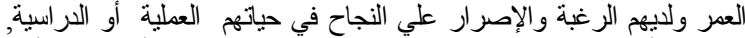

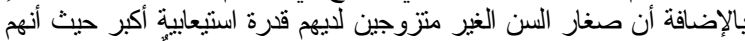

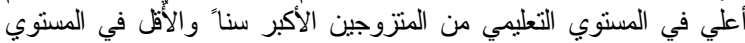

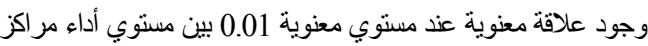
التعليمي.

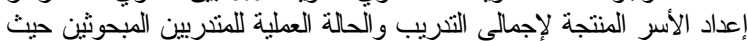

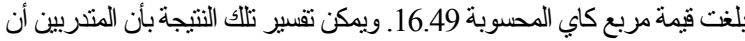

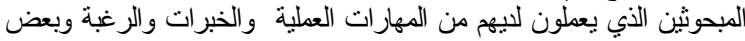

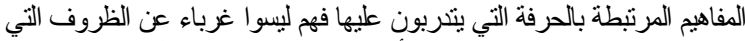

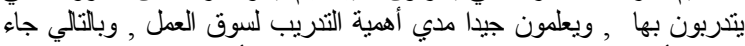

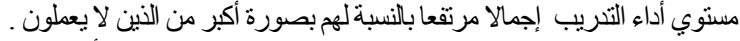

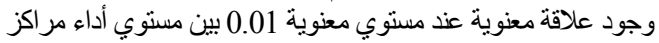

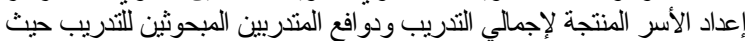

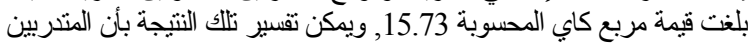

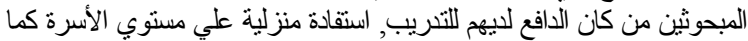

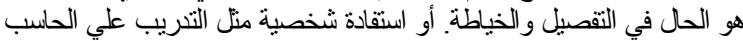

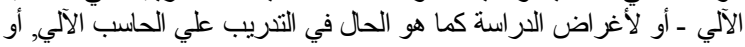

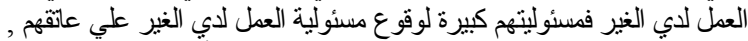

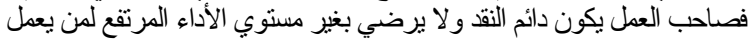

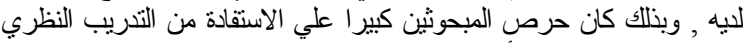

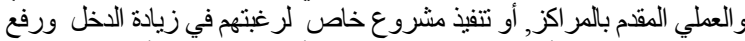

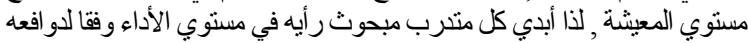

وبناء علي هذه النتائج فإنه يمكن رفض الفرض الإحصائي بالنسبة للتدريب.

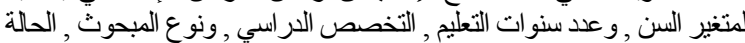

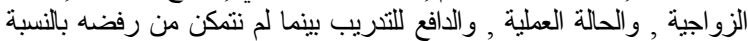
لكتغيري علد أفراد الأسرة , و علاقة العمل بالتندريب.

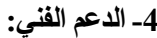

أـ نتائج التحليلّ الإحصائي باستخدام معامل الارتباط البسيط:

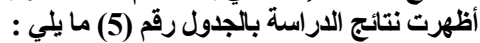

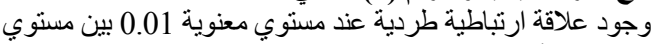

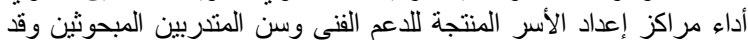
بلغت قيمة معامل الارتباط البسيط المحسوبة 0.175, ويمكن تفسير تلإنك 
وبناء علي هذه النتائج فإنه يمكن رفض الفرض الإحصائي بالنسبة

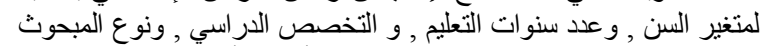

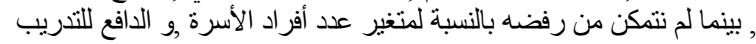

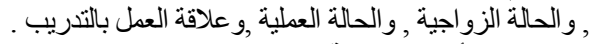
6- إجمالي الأدوار التنموية:

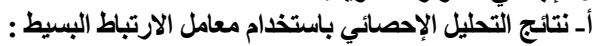

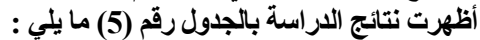

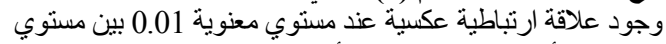

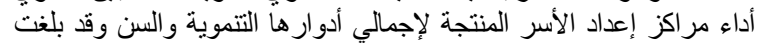

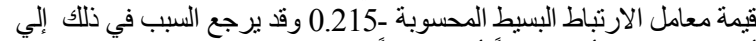

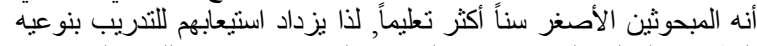

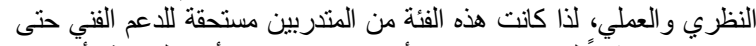
تكون سببا مبانشراً للارتقاء بمستوي أداء مر اكز إعداد الأسر المنتجة لأدوارها لأنها التنموية.

وجود علافة ارتباطية طردية عند مستوي معنوية 0.01 بين مستوي

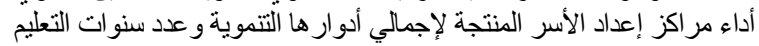

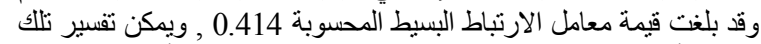

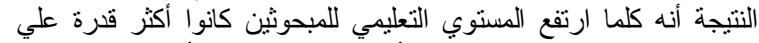

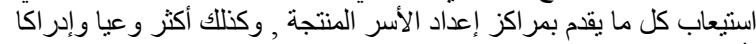

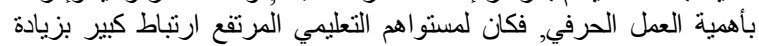
مستوي أداء المر اكز لأدوار ها التنموية . لمبن
بـ نتائج التحليل الإحصائي باستخدام مريع كاي:

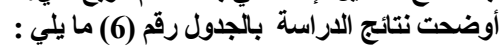

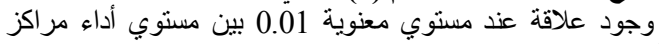

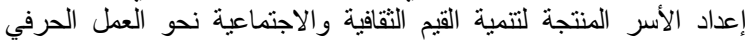

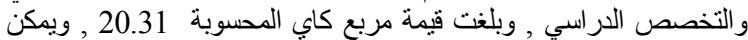

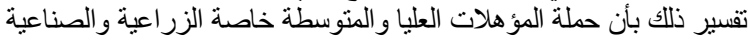

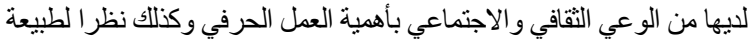

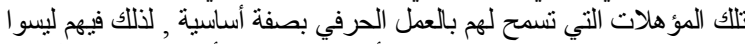

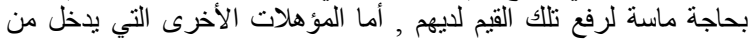

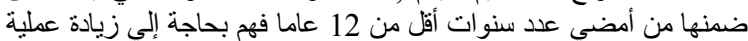

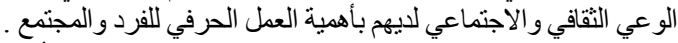

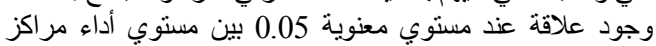

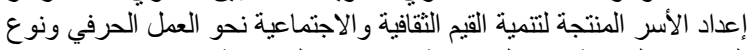

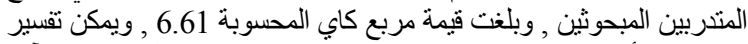

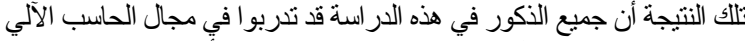

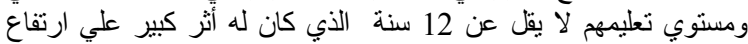

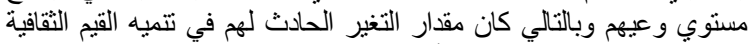

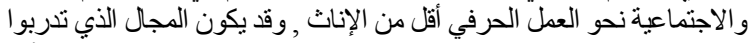

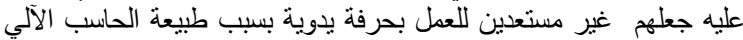

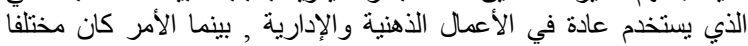

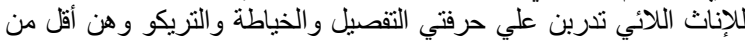

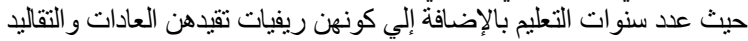

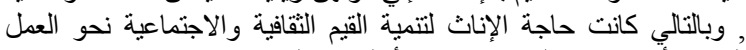
الحرفي أكبر وحدث لهن تغير بنسبة أعلي من الذكور.

جدول 5 ـ قيم معامل الارتباط البسيط المحسوبة بين المتغيرات الايموجرافية والاجتماعية للمتربين المبحوثين ومستوي أداع مراكز إعداد الأسر المنتجة لأدوارها التنموية

\begin{tabular}{|c|c|c|c|c|c|c|}
\hline \multirow[b]{2}{*}{ إجمالي الأدوار } & \multicolumn{5}{|c|}{ الأدوار } & \multirow{2}{*}{ المتغيرات المستقلة } \\
\hline & القيم الثقافية & الاعم الفني & إجمالي التذريب & التدريب العملي & التلريب النظري & \\
\hline$* * 0.215$ & *0.146- & $* * 0.175$ & $* * 0.228$ & $* * 0.234$ & *0.155- & 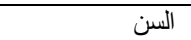 \\
\hline$* * 0.414$ & *0.156- & *0.239- & $* * 0.633$ & $* * 0.564$ & $* * 0.539$ & عدد سنو ات التعليم \\
\hline 0.040 & $0.107-$ & 0.114 & $0.065-$ & 0.058 & 0.068 & عدد افراد الأسرة \\
\hline
\end{tabular}

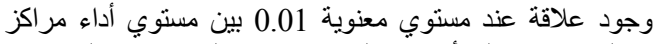

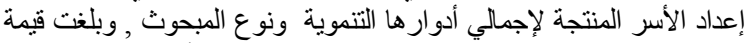

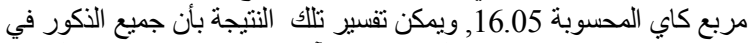

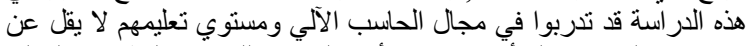

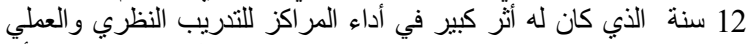

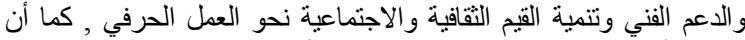

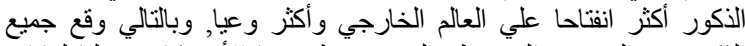

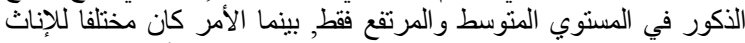

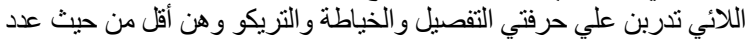

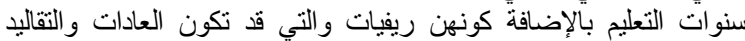

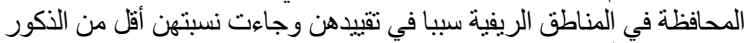

في مستوي الأداء المرتفع و المتوسط.
بـ نتائج التحليل الإحصائي باستخدام مربع كاي:

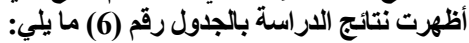

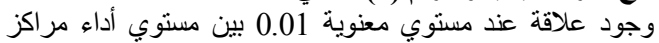

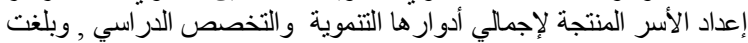

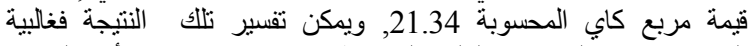

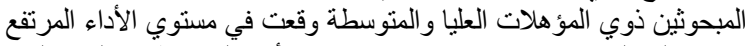

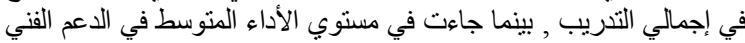

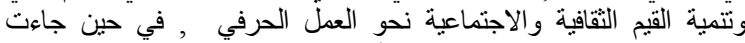

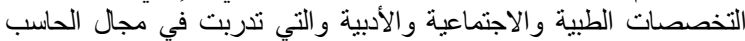

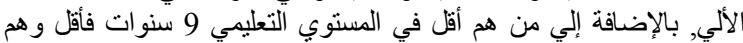

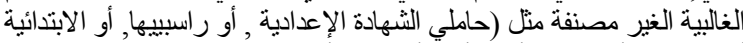

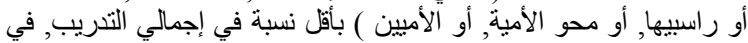

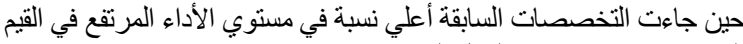
الثقافية والاجتماعية نحو العمل الحرفي .

جدول 6. قيم " مربع كاي " للعلاقة بين بعض المتغيرات الديموجرافية والاجتماعية للمتدربين المبحوثين ومستوي أداء مراكز إعداد الأسر المنتجة

\begin{tabular}{|c|c|c|c|c|c|c|c|}
\hline \multirow[b]{2}{*}{ إجمالي الأدوار } & \multicolumn{5}{|c|}{ الأدوار التنموية } & \multirow{2}{*}{\multicolumn{2}{|c|}{ م المتغيرات المستقلة }} \\
\hline & القيم الثقافية & الاعم الفني & إجمالي التذريب & التّريب العملي & التدريب النظري & & \\
\hline$* * 21.34$ & $* * 20.31$ & $* * 19.25$ & $* * 50.97$ & $* * 33.52$ & $* * 34.96$ & التخصص الدر اسي & 1 \\
\hline$* * 16.05$ & *6.61 & $* * 25.41$ & $* * 37.33$ & $* * 32.33$ & **19.30 & 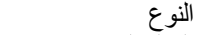 & 2 \\
\hline 3.01 & 2.66 & 5.04 & **10.87 & $* * 11.52$ & 5.61 & الحالة الزواجية & 3 \\
\hline **12.48 & 3.32 & 1.93 & $* * 16.25$ & $* 8.67$ & **12.69 & الحالة العطلية & 4 \\
\hline 1.72 & 4.82 & 1.61 & 2.37 & 4.24 & 0.959 & علاقة العمل بالتدريب & 5 \\
\hline$* 11.08$ & 7.77 & $* * 41.70$ & $* * 15.73$ & $* * 20.50$ & **16.49 & الدافع للتندريب & 6 \\
\hline
\end{tabular}

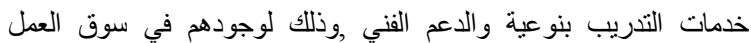

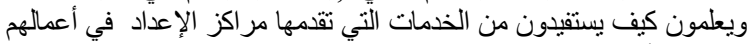

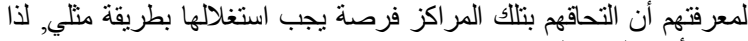
جاء الأداء بالنسبة إليهم مرتفعا .
وجود علاقة عند مستوي معنوية 0.01 بين مستوي أداء مراكز

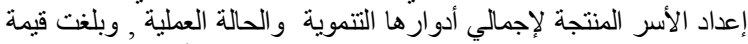

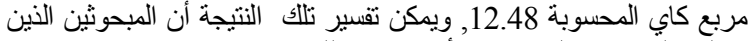

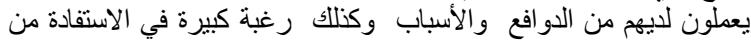


أ. جاءت في المرتبة الأولي مشكلة ارتفاع قيمة الاشتر الك الثهري بنسبة 83.3

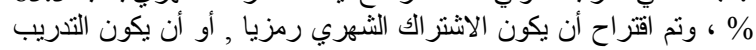

مجانيا.

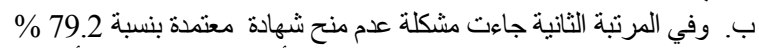

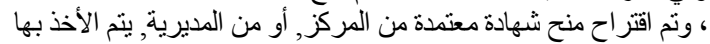

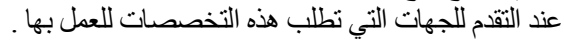

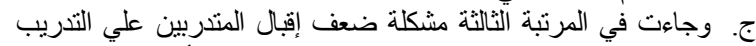

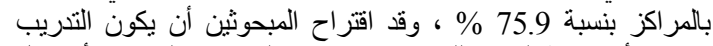

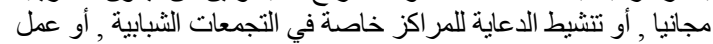

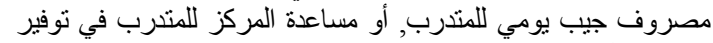

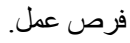

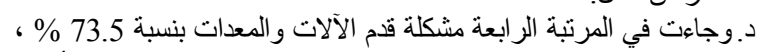
وقد اقترح المبحوثين ضرورة نواتية الرفير آلات ومعدات جديدة، مع أهمية

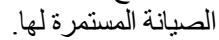

ه. وجاءت في المرتبة الخامسة مشكلة ارتفاع أسعار خامات التدريب بنسبة

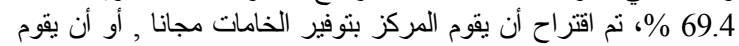
المركز بتوفير تللك الخامات بسعر الجملة.
وجود علاقة عند مستوي معنوية 0.05 بين مستوب أداء مراكز

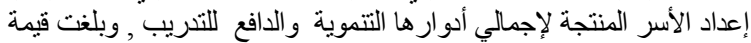

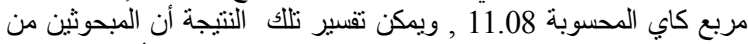

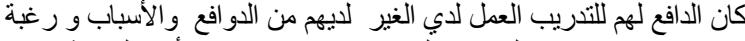

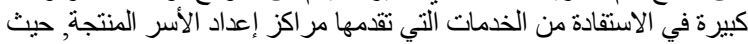

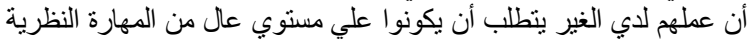

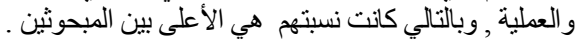

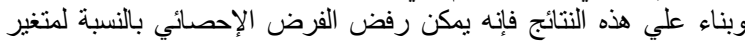

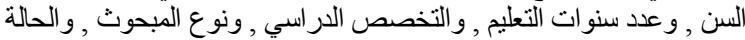

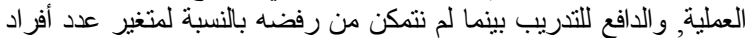

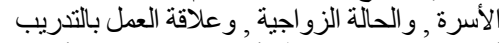

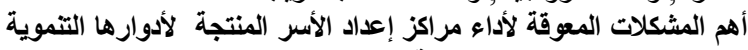

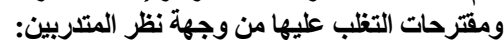

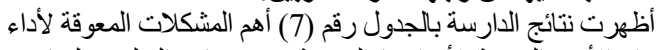

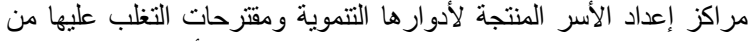
وجهة نظر المندربين وتم ترتيب هذه المشكلات تبعا لأهينها النسبية علي التي

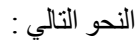

جدول7. أهم المشكلات المعوقة لأداء مراكز إعداد الأسر المنتجة ومقترحات حلها من وجهة نظر المتدربين.

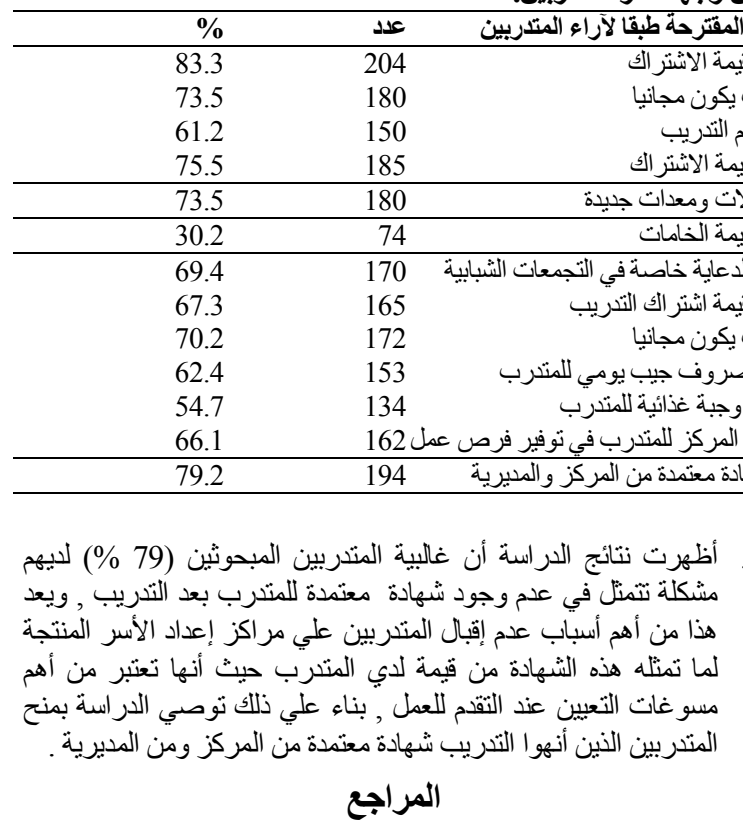

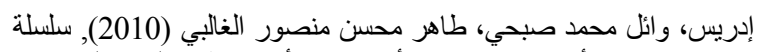

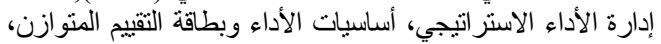
دار الميسرة للنشر والتوزيع والطبي، الطباعة، عمان، الأردن.

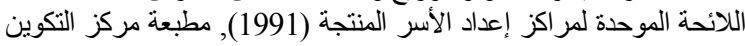

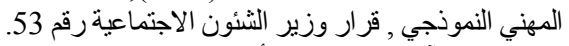

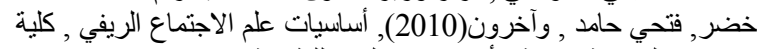

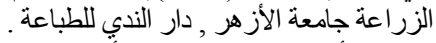

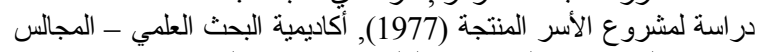

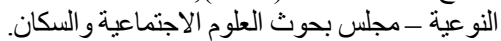

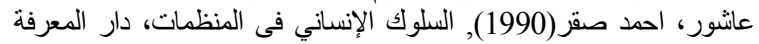
الجامعية، الإسكندرية.

عبد الوهاب، على محمد (1991), إدارة الأفراد، مكتبة عين شمس، القاهرة .

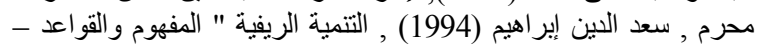

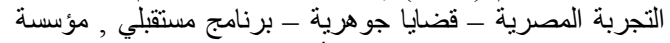
فريدريش ناومان مصر , العدد الأول , النانشر مؤسسة فرئة فيدريش

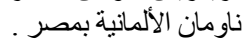

مركز المعلومات ( 2009), ديو النان عام محافظة الجيزة .

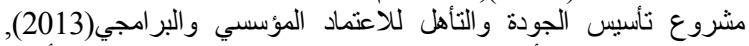

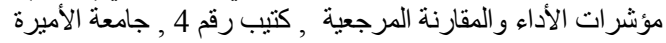
نورة بنت عبد الرحمن , المملكة العربية السعودية ـ العنة

\begin{tabular}{|c|c|c|c|}
\hline$\%$ & علد & 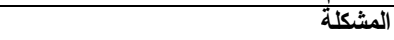 & p \\
\hline 83.3 & 204 & ارتفاع قيمة اشتر اك التدريب & 1 \\
\hline 73.5 & 180 & قدم الآلات و المعدات & 2 \\
\hline & & & 3 \\
\hline 75.9 & 186 & ضعف إقبال المندربين علي التدريب بالمركز & 4 \\
\hline
\end{tabular}

$79.2 \quad 194$

* 5

من خلال النتائج التي توصل إليها البحث الراهن يمكن استخلاص مجمو عة التوصيات التالية:

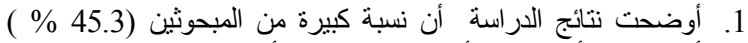

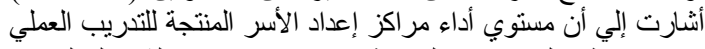

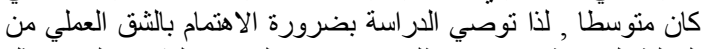

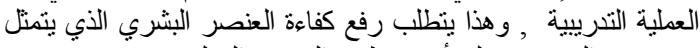

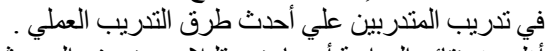

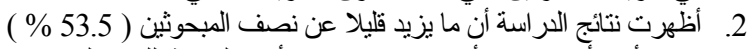

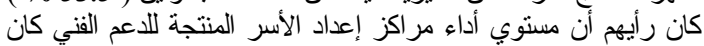

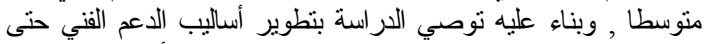

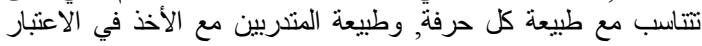

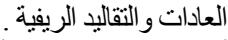

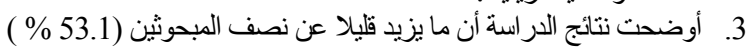

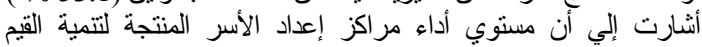

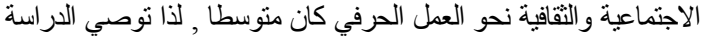

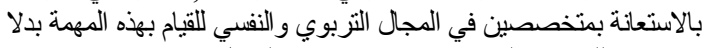

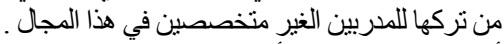

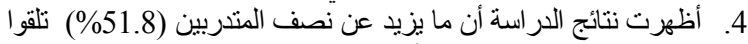

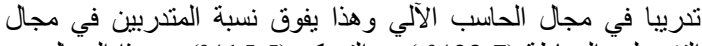

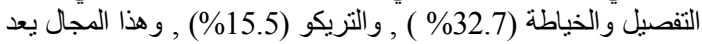

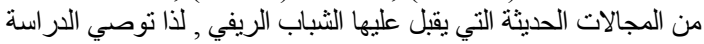

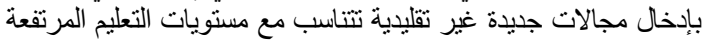

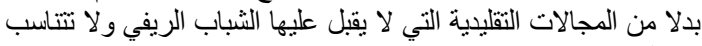

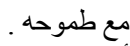

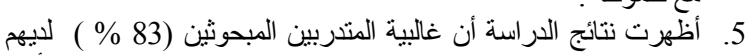

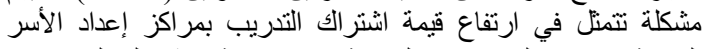

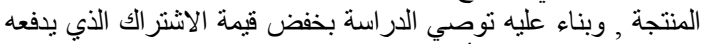
المتدرب مقابل التدريب أو جعله مجانيا . 
Joho ,Marven Cevicihetal(1986) ,Managin Performance ,Business Publishing, Colin . London.

Kregice, R.V. and Morgan (1970), D.W. Educational and Psychological_ Measurement. College Station, Durham, North Carolina, U.S.A.
Bhaskar, Indu \& Geethakutty ( 2001), Role of Nongovernmental organizations in rural development. Journal of Tropical Agriculture, India

Charles J. Coleman (1979), Performance Standards and Appraisal: The Bridge From leadership to Control to Development, Personnel: An Open System Approach, Winthrop Publishers INC, Cambridge, Massachusetts, Rutgers University.

\title{
Performance Level of the Productive Families Preparation Centers for their Developmental Roles and Its Relation to some Demographic and Social Variables Related to the Trainees in Rural Areas of Giza Governorate Ibrahim, I. F. A.; E. A. M. Heikal and Suzan M. M. Nasrat Rural Sociology and Agricultural Extension depet. Faculty of agriculture, Cairo University
}

\begin{abstract}
The present research aims to: 1 . Identifying the performance level of the rural preparation centers of the productive households for their developmental roles from the point of view of trainees,2. Determine the nature of the relationship between the performance level of productive families preparation centers for their developmental roles and some of the demographic and social variables of the trainees,3. Identify the most important problems hindering the performance of the productive families preparation centers and proposals to overcome them from the point of view of the trainees. The field study was conducted in 8 villages belonging to Al-Badrasheen, Abu Al-Nomros, Al-Saff, Giza, The sample size was 245 trainees from the trainees in the fields of tailoring, knitting and computerization at the productive families preparation centers the villages of Abu Ragwan Qabli, Azizia, Mazghouna, Shabramant, Tarsa, Zawia Abu Musalam, Nazlat Alian and Shoubak Al Sharqi. The data were collected using a questionnaire for a simple random sample of trainees during the months of February, March and April 2018, after being tested initially and making the required adjustments. The percentages, replicates, Pearson's simple correlation coefficient, and Chi square test for data analysis, description and presentation of results. The main results of the research can be summarized as follows: $1-51 \%$ of the trainees believed that the performance level of the productive families preparation centers for their development roles was average, while $42 \%$ of the trainees believed that the performance level of the productive families preparation centers for their developmental roles was high, while $7 \%$ of the trainees believed that the performance level of the productive families preparation centers for their developmental roles was low. 2- There was a positive correlation between the performance level of the productive families preparation centers for their developmental roles and the years of education of the trainees, The simple coefficient of correlation was 0.414 . 3- The existence of an inverse correlation relationship at a significant level of 0.01 between the performance level of the productive families preparation centers for their developmental roles and the age of the trainees. The value of the simple correlation coefficient was -0.215 . 4- The existence of a significant relationship between the performance level of the productive families preparation centers for their development roles and the following: (Specialization study, trainee type, practical situation, and motivation for training). The values of the calculated chi square were $21.43,16.05,12.48$ at a significant level of 0.01 , and 11.08 at a significant level of 0.05 respectively. 5- The problem of increasing the value of the monthly subscription ranked first among the most important problems impeding the performance of the productive families preparation centers for their developmental roles, as it reached $83.3 \%$ according to the opinions of the trainees, followed by the second problem of not granting an approved certificate with $79.2 \%$ The problem of equipment is old was ranked fourth with a rate $73.5 \%$. The problem of materials training prices came in fifth place with $69.4 \%$.
\end{abstract}

Keywords: Rural development, Egyptian countryside, Role, Training, and productive families preparation centers. 